Illinois State University

ISU ReD: Research and eData

Theses and Dissertations

$10-22-2021$

\title{
Aid Worker Burnout as Injury: Policy Implications for the Aid Sector
}

Melissa Lynn Quimby

Illinois State University, melissaquimby@yahoo.com

Follow this and additional works at: https://ir.library.illinoisstate.edu/etd

\section{Recommended Citation}

Quimby, Melissa Lynn, "Aid Worker Burnout as Injury: Policy Implications for the Aid Sector" (2021). Theses and Dissertations. 1502.

https://ir.library.illinoisstate.edu/etd/1502

This Thesis is brought to you for free and open access by ISU ReD: Research and eData. It has been accepted for inclusion in Theses and Dissertations by an authorized administrator of ISU ReD: Research and eData. For more information, please contact ISUReD@ilstu.edu. 


\section{AID WORKER BURNOUT AS INJURY: POLICY IMPLICATIONS FOR THE AID SECTOR}

\section{MELISSA L. QUIMBY}

\section{Pages}

Background: Aid work is a valuable service provided to the world's most vulnerable people, and it can often be dangerous, exposing workers to such security concerns as isolation, contagious diseases, and trauma. The chronic stressors that often accompany aid work can result in the debilitating effects of burnout, the symptoms of which are defined here as emotional exhaustion, depersonalization, and decreased personal achievement. There is a gap in the literature describing how aid organizational culture contributes to the prevalence and severity of aid worker burnout that this research intends to fill. Applied research focus: I investigated the concept of burnout as an "injury" inflicted upon workers by poorly structured organizations in a highly competitive sector. This research explores the motivational factors that lead a person to a career in aid work and which organizational-based strategies they feel best prevent the symptoms of burnout from appearing. Methods: I employed mixed-methods approach including an autoethnography, semi-structured reflexive interviews with ten international aid workers, and a brief online poll of aid workers. Qualitative data were analyzed using MAXQDA and quantitative data were collected and analyzed with Qualtrics. Findings: It is the aid sector itself, being highly competitive, donor-dependent, and disaster and conflict-driven that leads to excessive workloads being placed on aid workers. Donor agencies and aid organizations have a moral imperative to avoid placing unnecessary burdens on aid workers and to protect both their personal well-being and their ability to perform on behalf of their program recipients. 
Conclusion: Aid workers will continue to burn out, regardless of their personal coping mechanisms, if the aid sector does not resolve to collaborate to address this problem and take concrete measures to reduce the stressors and frustrations common in the aid sector. A list of such measures created with input from both interviewees and survey respondents is provided. KEYWORDS: Aid Organization; Aid Worker; Burnout; Humanitarian Aid; Mental Health; Staff Wellness 
AID WORKER BURNOUT AS INJURY: POLICY IMPLICATIONS FOR THE AID SECTOR

MELISSA L. QUIMBY

A Thesis Submitted in Partial Fulfillment of the Requirements for the Degree of

MASTER OF SCIENCE

Department of Sociology and Anthropology

ILLINOIS STATE UNIVERSITY 
Copyright 2021 Melissa L. Quimby 
AID WORKER BURNOUT AS INJURY: POLICY IMPLICATIONS FOR THE AID SECTOR

MELISSA L. QUIMBY

COMMITTEE MEMBERS:

Michael Dougherty, Chair

Christopher Wellin

Marion Willetts 


\section{ACKNOWLEDGMENTS}

I am forever in the debt of my graduate advisor Dr. Mike Dougherty for his unflagging support and encouragement from the very moment I selected my research topic up until the final draft of this thesis. His perspective and guidance were instrumental in shaping the direction of my analysis. I would also like to express my deep gratitude to Dr. Chris Wellin for teaching me the joy of qualitative research and Dr. Marion Willetts for her critical eye and feedback. Their comments were invaluable to my thesis and their patience much appreciated. I could not have requested a better committee.

Special thanks must go to each of the participants of my study for taking the time from their busy lives, dealing with communication issues and different time zones, sharing difficult stories, and answering my follow up emails. They and other humanitarian aid workers are out there making untold sacrifices as they strive to make the world a better place and I am proud to know them. It is my greatest wish that their contribution to this research results in making aid work a kinder and more effective profession.

I would like to thank S. Sender and S. DeGuzman for reading my thesis out of pure interest and offering encouragement and constructive comments. They set a fire under me in the final days of editing, and I truly appreciate them both.

Finally, I would like to express my gratitude for my family and boyfriend who believed in me so much that I began to believe in myself, too.

M.L.Q. 


\section{CONTENTS}

Page

ACKNOWLEDGMENTS

FLOWCHARTS V v

CHAPTER I: INTRODUCTION AND BACKGROUND 1

Introduction $\quad 1$

$\begin{array}{ll}\text { Background } & 3\end{array}$

A Brief Description of Aid Work

$\begin{array}{ll}\text { Definition of Burnout } & 6\end{array}$

$\begin{array}{ll}\text { Sociological Significance } & 7\end{array}$

CHAPTER II: A REVIEW OF THE LITERATURE $\quad 8$

$\begin{array}{ll}\text { Burnout as Injury } & 8\end{array}$

The Emotional Motivations of Aid Workers 9

Pro-Social Motivations: Empathy, Connection, and Altruism 9

Self-Interested Motivations: Compensation and Exhilaration $\quad 10$

$\begin{array}{ll}\text { Personal Coping Mechanisms } & 12\end{array}$

$\begin{array}{ll}\text { Organizational Factors in Creating Stress } & 12\end{array}$

$\begin{array}{ll}\text { Organizational Factors Mitigating Stress } & 13\end{array}$

CHAPTER III: RESEARCH METHODOLOGY 17

$\begin{array}{ll}\text { Research Questions } & 17\end{array}$

$\begin{array}{ll}\text { Design and Data Collection } & 17\end{array}$

Qualitative Method: Autoethnography 18

Qualitative Method: Semi-Structured Reflexive Interviews 19 
The Very Nature of The Aid Sector Increases Burnout among Staff

Excessive Workloads Devastate Mental and Physical Health

Excessive Workloads Are the Primary Culprit Regarding Burnout

Competitive Nature and Focus on Growth

Donor-Dependency

Burdensome Reporting Requirements

Burdensome Coordination Efforts Required

The Nature of Disaster and Conflict Response Increases Burnout/Injury

Unpredictable and Overwhelming Need

Impermanent Nature of Aid Work

The Aid Sector's Inherent Insecurity Increases Burnout

Security Issues

Restricted Movement of Staff

The Aid Sector Increases Reluctance to Seek Mental Health Assistance

Stigma

Machismo and Sexism

Competitive Nature of the Aid Sector

Poor Management and Organizational Practices

Management Unable to Resolve Burnout-Related Issues 
Lack of Boundaries, Expectation of Working on Weekends and Holidays

Management Insufficiently Aware of Signs of Burnout

Inadequate Human Resources Practices 48

Managers Untrained in People or Program Management Skills 50

Fear of Legal Liability $\quad 52$

Inadequate Housing or Non-Family Postings 53

Why Aid Workers Accept Excessive Workloads and Poor Working Conditions 54

Aid Worker Work Ethic and Altruistic Nature $\quad 54$

Reluctance to Seek Assistance $\quad 56$

Delayed Reaction to Burnout/Injury $\quad 57$

Socializing with Others in the Aid Sector Is a Double-Edged Sword 57

CHAPTER V: IMPLICATIONS AND CONCLUSIONS

$\begin{array}{lr}\text { Policy Implications } & 59\end{array}$

$\begin{array}{ll}\text { Policy Recommendations for the Aid Sector } & 60\end{array}$

$\begin{array}{ll}\text { Strengths And Limitations } & 62\end{array}$

$\begin{array}{ll}\text { Suggestions for Further Research } & 62\end{array}$

$\begin{array}{ll}\text { Conclusion } & 63\end{array}$

$\begin{array}{lc}\text { REFERENCES } & 66\end{array}$

APPENDIX A: PARTICIPANT DEMOGRAPHICS AND EXPERIENCE 73

APPENDIX B: AID WORKER INTERVIEW GUIDE 75

$\begin{array}{ll}\text { APPENDIX C: AID WORKER POLL } & 77\end{array}$ 


\section{FLOWCHARTS}

Flowchart $\quad$ Page

1. The aid sector is competitive and donor-dependent 29

2. The aid sector is disaster and conflict-driven and therefore unpredictable and unreliable 34

3. Inherent insecurity and restricted movement of staff 36

4. Aid sector factors causing reluctance or delay in seeking help 39

5. Poor management and organizational practices contributing to burnout/injury 43 


\section{CHAPTER I: INTRODUCTION AND BACKGROUND \\ "It's better to burn out than to fade away." - Neil Young}

\section{Introduction}

My hand fell off the steering wheel and dropped to my lap as I drove from the Nairobi Hospital to my office just a few kilometers away. Everything seemed to move in slow motion as I continued to drive with my other hand and tried to process what was happening. Was I having a stroke? Unable to lift my hand more than an inch off my lap and only with great concentration and effort, I pulled over and called the driver to bring me back to the hospital. By the time he arrived just a few minutes later, I had lost all strength and feeling in my right arm and leg and my lips were so numb I could have stuck needles in them. Back at the hospital, the doctor who had just performed my previously routine end-of-mission exam told me that I was numb from hyperventilating and had me breathe into a brown paper bag. About ten minutes later the feeling returned to my extremities and I was able to walk normally again. I had five days left in Nairobi and from that time on I experienced eight or nine episodes of partial paralysis, mostly on the right side of my body, once on the left, and once all over my body when I slithered out of my office chair and laid on the floor for about 15 minutes until it passed. It was a miserable end to an extremely stressful assignment.

This was neither my first experience with extreme stress and poor health as a humanitarian aid worker, nor would it be my last. In the Dominican Republic, I was once so sleep deprived from working around the clock for several weeks that my hair fell out in clumps, and I was reluctant to drive myself for fear that I might fall asleep at a stoplight. In Haiti, I took up smoking to deal with multiple stressful situations and would wake up at 2:00 am and chain- 
smoke on my terrace until sometimes as late 4:00 am. In Ghana, I developed a blood clot while driving 14 hours in one day, which I did not discover until it caused a potentially lethal pulmonary embolism. When my supervisor from the assignment where I had experienced partial paralysis - the single most traumatic event of my life - wrote to me two years later asking if I wanted to work with him again in another country, I accepted without hesitation.

Clearly, I know how stressful and unhealthy humanitarian aid work can be. I worked more than thirteen years in the aid sector implementing and managing community health projects, emergency food distributions, and disease prevention campaigns around the world. I worked in situations of extreme need, emergency and disaster responses, high security risk areas, and a conflict zone. I had not only experienced truly debilitating episodes of burnout myself but saw firsthand and heard multiple personal accounts of other aid workers' experiences with burnout. In that time, I noticed that when I was burning out, my manager or close colleagues were often also showing sure signs of burnout, creating a source of stress that aggravated or even provoked my own symptoms.

And yet, I continued to seek out and accept such assignments, as have many of my friends and colleagues. This willingness to continue to work under sometimes debilitating - even life-threatening - circumstances eases the pressure on aid organizations to truly improve their staff wellness policies and working conditions. It was because I personally experienced and witnessed serious problems related to burnout with multiple contributing factors - both within specific settings as well as the broader aid sector - and my seemingly inexplicable desire to continue to work in the sector that I was inspired to conduct this research. I set out to discover how to make aid work less harmful through both personal reflection and the perspective of 
seasoned professionals. I do this so that the aid sector - with its mission to help people - can more effectively provide its services without harming anyone in the process.

\section{Background}

The aid sector has a relatively long history, one which could be said to have started with European countries sending assistance to and building infrastructure in their colonies and which expanded further post-World War II with the US Marshall Plan (Phillips 2013). Aid to foreign countries was not seen as an act of charity but rather a mutually beneficial arrangement, such as how the Marshall Plan restored the economic viability of European nations and they in turn purchased manufactured goods from the US (O'Hare 2017). During the Cold War, starting in the 1960s, the Development Assistance Committee (DAC) was created to better coordinate aid from several donor countries to the poorest countries (Edwards 2014).

Since the emergence of neoliberal globalization in the 1970s there has been an erosion of the quality of life and heightened vulnerability for a wide swath of the global population. This led to a "growth spurt" of non-governmental and non-profit organizations of more than 200,000 (Foster and Fine 2007) and, along with them, an accompanying increase in the number of humanitarian aid workers volunteering or working for them. This growth spurt was paradoxically occurring at a time when people otherwise seemed to be dropping out of political activities such as voting, party affiliation, and union membership (Salamon 1994). Of these nonprofit organizations, 144 reached $\$ 50$ million in annual revenue by tailoring themselves specifically to the needs of the corporations or governments that fund them (Foster and Fine 2007). Since then, there has been a further move away from state-to-state aid towards for-profit firms competing for international aid programming funds. Among the top vendors receiving contracts from the 
United States Agency for International Development (USAID) in 2012, four were for-profit organizations (Chemonics, John Snow, Inc, Development Alternatives Inc, and Abt Associates) collecting a total of over $\$ 1.8$ billion, more than the two non-profit organizations (Partnership for Supply Chain Management and Family Health International) collecting \$723.8 million and two governments (Pakistan and Jordan) receiving $\$ 745.2$ million combined (Casey 2016).

As the humanitarian aid sector continues to provide funding, programming, and services to people around the world, it increasingly suffers from the symptoms commonly associated with burnout, with traumatic, vicarious, and chronic stress taking a toll on both individual aid workers as well as their organizations (Curling and Simmons 2010). It is inherently stressful and oftentimes dangerous work, with aid workers exposed to all manner of risk. The Aid Worker Security Database of the London-based Humanitarian Outcome organization reports that between 1997 and 2018, there were 1,830 deaths, 1,365 kidnappings with live release or escape, and 1,700 wounded aid workers around the world. They are also exposed to poor living conditions, contagious diseases and illnesses, and intentional attacks (Van Brabant 2000).

Recognized more often as particularly harmful to mental health, chronic stressors abound in aid work. These stressors have been linked to what is commonly called "burnout," described by the National Institutes of Health as a "prolonged response to chronic emotional and interpersonal stressors on the job... defined by the three dimensions of exhaustion, cynicism, and inefficacy" (Maslach, Schaufeli, and Leiter 2001). Burnout can manifest as listlessness or the inability to cope, alienation from work-related activities, and/or reduced work performance. This reduced work performance not only harms the aid workers themselves but also their organizations and ultimately, the people depending on those organizations for assistance. 
Although much of the research into stress and burnout has been focused on the individual, there is still a lack of research into what "the provision of effective staff support" should look like (Curling and Simmons 2010). The definition of "staff care" is defined by USAID as "broad issues ranging from personal emergency preparedness and response to staff wellness on a day-to-day basis, including physical and psychological well-being in the workplace" (Porter and Emmens 2009). However, although most humanitarian aid organizations recognize their importance and have officially adopted staff care plans, they are either inconsistently adhered to or fail to meet their own minimum standards (2009).

\section{A Brief Description of Aid Work}

The aid sector comprises development assistance and humanitarian aid, both of which can be made more complex by conflicts or outbreaks of disease. The Humanitarian Coalition describes them in more detail below:

\footnotetext{
Humanitarian aid is designed to save lives and alleviate suffering during and in the immediate aftermath of emergencies, whereas development aid responds to ongoing structural issues, particularly systemic poverty, that may hinder economic, institutional and social development in any given society, and assists in building capacity to ensure resilient communities and sustainable livelihoods. Both humanitarian and development aid are related, and different forms of aid often have both humanitarian and development components. Development aid can exist without humanitarian aid (in developing countries that do not have humanitarian crises), but it also often exists in addition to humanitarian aid during and after crises. For example, if an earthquake strikes a country, short-term humanitarian aid is needed. This includes the delivery of food and water, the provision of temporary shelter, as well as health services (Humanitarian Coalition, n.d.).
}

The terms "humanitarian aid" or "development work" can conjure up romantic - or not so romantic - ideas of a person from a wealthy country rushing to the aid of those in need in a lessdeveloped country. In fact, aid workers come from many different countries and backgrounds and wealthy countries also suffer from natural or human-made disasters and pockets of poverty. Aid operations may vary widely in size and length, but all require contact with host country nationals, whether government officials or recipients of the aid, and the input of many people 
with different areas of expertise. Working in the aid sector therefore requires a person to have not only the necessary technical knowledge to implement an aid program but the ability to live and work with people from different cultures and to treat all people with dignity.

\section{Definition of Burnout}

There is not a firm consensus in the literature on the many attributes of burnout, and the symptoms of stress leading to burnout vary. More common in professions with long hours and intense interactions with clients, burnout occurs in workers with high levels of workplace frustrations (Maslach, Schaufeli, and Leiter 2001). These frustrations act as a precursor to burnout when the labor process itself interferes with worker-client relationships, when workers feel isolated or powerless, and when they are burdened with excessive rules and bureaucratic procedures (Lewandowski 2003). This supports the argument that worker burnout is not independent of organizational failures.

Blanchetière (2006) comprehensively describes the physical, emotional, behavioral, and spiritual symptoms of burnout, which can manifest as the inability to relax, mood swings, guilt and shame, irritability, problems with relationships, indecisiveness, self-criticism, and loss of purpose or hope. Similarly, Curling and Simmons (2010) describe the tension headaches, body aches, difficulty with appetite or sleeping, tension and nervousness, irritability and physical and/or mental fatigue or exhaustion that were reported by aid workers who were experiencing stress. Maslach (1993) has developed the most widely accepted description, that of a psychological response to chronic stressors which lead to emotional exhaustion, depersonalization, and the feeling of reduced personal accomplishment. I employed Maslach's 
more concise definition of burnout in my surveys and interviews but drew upon the more detailed symptoms outlined above while coding and searching for themes in the qualitative data.

\section{Sociological Significance}

Humanitarian aid work continues unabated around the world as global spending on aid steadily increased in the last decade, reaching a total of $\$ 152.8$ billion in 2019 (OECD 2020). By 2030, the effects of climate change alone are predicted to increase the demand for humanitarian aid services by 50\% (UN World Meteorological Organization 2021). As the sector grows and employs ever more workers, the proliferation of burnout expands, becoming increasingly commonplace. MacPherson and Burkle (2020) described the present outlook on aid worker burnout:

The possibility of developing a psychological problem because of aid work has increased along with the rise in levels of disease, injury, kidnapping, and assault. As a result, expressions of traumatic stress have become the norm rather than an exception (MacPherson and Burkle 2020:).

Taking concrete measures to reduce burnout within the aid sector and build resiliency will produce positive outcomes for all stakeholders. Organizations would benefit from reduced staff turn-over, improved morale, and more successful missions. Aid workers would experience improved personal security and a sense of well-being, and program recipients will receive more empathetic and effective support (Blanchetière 2006). 


\section{CHAPTER II: A REVIEW OF THE LITERATURE}

My approach in reviewing the available literature was to focus on both individual humanitarian aid workers and on aid organizations to piece together a more comprehensive picture of the different factors that contribute to or mitigate the symptoms of burnout. I wanted to better understand the different motivations of aid workers and their personal coping mechanisms to discover if there were certain attributes that made them more or less likely to suffer from burnout. I also wanted to learn more about how aid organizations' cultural and management styles could either be a source of stress serving to undermine employee health, or act as a protective shield to prevent burnout. Early on, I read the work of Damania (2019) on "moral injury," which seemed to describe what I had been seeing in the aid sector a bit more accurately.

\section{Burnout as Injury}

Zubin Damania, MD (2019), argues that the term "burnout" places the blame on the victim, essentially saying “you are not resilient enough, have you tried yoga?" and suggests we use the phrase "moral injury" instead. Moral injury speaks to the unhealthy working environments or expectations often seen in healthcare settings that make it difficult to truly connect with the people you want to help. Damania states that people who work in poorly structured organizations, forced to make painful decisions due to financial concerns or burdened with so much work that they do not have time to connect with the people they are there to help, will only keep attempting to adapt until they finally "break" (Damania 2019). However, the generally accepted definition of moral injury is "a particular type of trauma characterized by guilt, existential crisis, and loss of trust that may develop following a perceived moral violation

(Jinkerson 2016). Because the injury inflicted upon aid workers is caused by more than guilt or 
loss of trust or any other moral issue, I will use the word "injury" without a modifier to describe more precisely what burning out actually entails.

\section{The Emotional Motivations of Aid Workers}

The sociology of emotions and the role emotions play in the lives of humanitarian aid workers is important but underrepresented in the literature. Emotions and emotion-laden principles such as altruism, empathy, and excitement-seeking through risk-taking behaviors are stronger motivations for aid worker than for workers in other sectors. Analysis reveals how social relationships can be formed, heightened, and strengthened by emotions (Durkheim 1912, Collins 1990) Hochschild's (1983) descriptions of "emotional labor" and "collective emotional labor" clarifies the challenges facing aid workers. Emotional labor "requires one to induce or suppress feeling in order to sustain the outward countenance that produces the proper state of mind in others" (1983: 7). This is particularly necessary when working with people who have suffered atrocity and/or trauma. Collective emotional labor occurs when volunteers provide the necessary emotional support to help others manage their own emotions (1983). I employ the work of Hochschild to frame my analysis of the motivations of humanitarian aid workers through the lens of emotions.

\section{Pro-Social Motivations: Empathy, Connection, and Altruism}

There is ample evidence that empathy and the desire for connection is a primary motivating factor in humanitarian activities (Doidge and Sandri 2019) with the "emotional belonging that comes from inter-cultural friendships likely acting as a protective force against the symptoms of burnout" (Heuser 2012:1427-1428). There is an intense camaraderie that comes 
from living in close quarters with colleagues (Roth 2015). Understanding the desire to connect with people and develop deep and trusting friendships goes a long way to discovering what motivates nonprofit workers and humanitarian aid workers. At the same time aid workers desire a "fundamental sense of life being worth living" (Schnell et al 2019: 168). Most aid workers list altruism or the opportunity to make a difference and a sense of calling to help others (Oberholster et al. 2013, McCormack and Bamforth 2019) as their prime motivation. In fact, altruism is more likely to see an aid worker through their more difficult challenges; "altruistic authenticity" provides a "deeply felt gratitude and privilege of responding to the call for help" which gave aid workers a feeling of triumph and exhilaration and helped them work through their fear to continue to provide assistance (McCormack and Bamforth 2019). So strong is altruism as a motivating factor in aid workers that the inability to achieve one's altruistic goals, such as seeing a malnourished child fail to improve, can be a source of frustration that causes them to question their contribution (Asgary and Lawrence 2014).

\section{Self-Interested Motivations: Compensation and Exhilaration}

Humanitarian aid workers who leave their friends and families for extended periods of time while working in uncomfortable or unsafe environments do so, of course, with varying degrees of self-interest. Economic compensation, the excitement of world travel, and the particularly intense camaraderie that comes from living in close quarters with colleagues (Brown and Yoshioka 2003, Oberholster et al. 2013, Roth 2015) are among the personal ambitions motivating people to engage in humanitarian aid work. Aid workers are not merely idealists but professionals who also prioritize their career development. 
While the desire for connection may explain the motivations of many humanitarian aid workers, some choose to live and work closely together in high-risk settings for short-term periods, making long-term relationship building more difficult but overall increasing the total number of people with whom they interact. These high-risk settings can be truly dangerous, as there has been an increase in the number of aid workers who were killed, kidnapped, or otherwise attacked since the 1990s (Roth 2015) with those that seek out such assignments knowing full well there is a possibility they could meet with death. Such risky behaviors have been dubbed "edgework" by Lyng (1990), defined as voluntary risk-taking that involves "a clearly observable threat to one's physical or mental well-being or one's sense of an ordered existence" (1990: 857). Two theories about why a person engages in such high-risk behavior are that individuals view edgework as a form of resistance to a repressive and alienating work environment and that edgework represents the difficulties of living in an at-risk society (Lyng 2005).

Roth (2015) expands upon edgework to refer to the type of humanitarian aid work specifically based in conflict zones or otherwise dangerous settings. Aid workers who choose high-risk dangerous assignments tended to be both male and relatively affluent compared to the average aid worker (Lois 2001) and they are attracted to an "exciting and stimulating work context, which is shaped by questions of life or death as well as a high degree of flexibility and independence" (Roth 2015). This simultaneously addresses both of Lyng's theories of edgework - the avoidance of a mundane or alienating workplace and the search for flexibility and selfdirectedness (2015). 


\section{Personal Coping Mechanisms}

Depending on the situation and the individual, personal coping mechanisms can prove to be variously effective and ineffective. Coping strategies deemed effective by aid workers were, in large part, social connections and healthy lifestyle activities such as engaging in exercise, meditation or other spiritual practices, and hobbies (Young, et al. 2018, Curling and Simmons 2010). Ineffective - yet still employed - coping strategies include unhealthy lifestyle activities, such as using alcohol, sleeping too much or too little, engaging in casual sex, and poor eating habits, as well as work-based activities, such as working harder or longer hours (Dahlgren, et al. 2009, Young, et al. 2018). A study of a large international aid organization found that aid workers were increasingly dependent upon negative coping mechanisms, defined as "the reliance on alcohol, cigarettes, prescribed or non-prescribed drugs and caffeine to manage stress" (Curling and Simmons 2010). The reliance on unhealthy coping mechanisms, along with the continued prevalence of burnout in the aid sector, strongly suggests that personal coping mechanisms are inadequate to fully ward off the symptoms of burnout.

\section{Organizational Factors in Creating Stress}

People who work in the nonprofit sector in general are motivated by a close identification and sense of belonging with their organization, so much so that they are at risk of "overidentification" in which an individual can lose sense of their autonomous self and be more easily

manipulated by their managers (Schnell et al. 2019). This can make them more vulnerable to the structure and policies of an organization that serve to frustrate staff and drive them away (Brown and Yoshioka 2003). The most commonly reported ways that organizations increase stress and frustration of their staff include excessive workload or long working hours, inability to achieve 
goals or make decisions, bureaucracy, lack of recognition of efforts or successes from management, job or economic insecurity, and a "macho" sector culture (Blanchetière 2006, Curling and Simmons 2010, Ager, et al. 2012, Asgary and Lawrence 2014, Young, et al. 2018). Worse, stress-related working conditions severe enough to be described as an intermediate or high "effort-risk imbalance" was associated with increased odds of experiencing the symptoms of burnout (Jachens, et al. 2019) as was exposure to chronic stressors (Ager 2012).

Additional sources of stress identified by aid workers include the inability to socialize and reduced personal freedom (Curling and Simmons 2010), which is quite common in high-risk duty stations where organizations tighten the reins in the name of physical protection of their staff, as well as insecurity, health risks, and attacks on personal well-being (Blanchetière 2006, Ager et al. 2012). Aid workers can also end up isolated from the local population when organizations hire mostly expatriate staff to "avoid corruption and to implement programs that challenge local practices" (Roth 2012: 1467). This organizational practice, seen as a "paternalistic myth" or rationalization, can lead expatriate staff to feel guilt or shame. Aid workers are highly cognizant of the disparity in salaries and living conditions between expatriate and local staff, and that younger expatriate staff were often inexperienced and lacking essential skills yet still earned much higher salaries than their local counterparts (2012). These negative feelings of isolation, guilt, and shame can act as a stressor on the aid worker.

\section{Organizational Factors Mitigating Stress}

Organizations, on the other hand, have tools available that can mitigate the effects of the chronic stressors that lead to burnout. In a literature review of 14 articles, organizational staff support was identified as an important determinant for mental health (Strohmeier and Scholte 
2015, Curling and Simmons 2010). Aid organizations can help ease the transition of a staff member starting a new assignment by providing them with a clear and complete briefing, especially to a high-security country. Thorough briefings can save considerable time upon arrival, reduce the workload, and avoid duplicating existing work (Roth 2015). Briefings also likely reduce the death rate, which is the highest in the first three months of an assignment, in part because workers are still learning about their new surroundings (Sheik et al. 2000).

Other mitigating organizational practices include arranging social activities, facilitating access to information on stress and stress management workshops, hiring trained staff counselors and peer helpers to support fellow staff members affected by stress or a crisis, anonymous surveys on staff morale, and the use of mediators to resolve staff grievances - all of which would lead to better morale, higher staff retention, and reduced sickness and absenteeism (Curling and Simmons 2010). Organizations that allocate time to their volunteers for reflection, introspection or deliberation, and the opportunity to reflect negatively when appropriate, can help avoid the symptoms of burnout (Downton and Wehr 1998) and cynicism (Kallman 2015). Younger, less experienced aid workers who receive quality assistance from their organizations gradually gain experience and hone their skills, which acts to increase their self-esteem and makes them more likely to sign up for another deployment (Albuquerque et al. 2018). Finally, improving personnel and field management, establishing a better work-life balance by requiring people to take time off, facilitating social support, offering institutionally supported mental health education, and conducting post-assignment debriefings and counseling sessions improve staff wellness (Asgary and Lawrence 2014).

Recently researchers have paid increasing attention to humanitarian aid worker burnout, especially as it negatively affects the organization, the workers, and aid recipients. The existing 
scholarly literature provides a window into the lived experiences of humanitarian aid workers vis-à-vis burnout and the coping mechanisms workers employ (with varying degrees of efficacy) to alleviate those symptoms. The literature also highlights the emotional motivations of aid workers such as empathy, altruism, and sense of camaraderie and excitement - motivations less central to labor in other employment sectors.

Aid organizations that focus on organizational commitment would improve employee morale and reduce the incidence of burnout (Mottaz 1998). Organizational commitment is characterized as a strong belief in the goals and values of the organization, a willingness to exert effort on behalf of the organization, and a strong desire to remain a member in the organization (Porter et al. 1974). The level of organizational commitment is considered a key factor in job performance (Fukami and Larson 1984) and therefore, should be of considerable interest to the humanitarian aid sector which cannot rely on stock options or other such incentives to attract high performing employees. What we see instead is a high rate of short-term contracts and low staff retention, with aid workers frequently moving from one organization to another.

While some research addresses organizational factors in causing and mitigating chronic stressors in humanitarian aid, and some research explores the affective dimension of worker motivation, little scholarship successfully integrates these two foci. In fact, aid workers are generally highly altruistic, empathetic, and emotionally attached to colleagues, community members and aid recipients. This affective investment leaves aid workers more vulnerable to organizational stressors than workers in other sectors because they are less likely to take a break if they are helping those in dire need. Existing literature fails to conceptualize burnout as an injury inflicted on staff through poor organizational practices. Aid organizations headquarters are staffed with people, especially those in human resources and senior management, who do not 
fully understand the type of people attracted to a career in international field work or the stresses inherent to that work. This leaves them unable to create effective staff wellness policies. 


\section{CHAPTER III: RESEARCH METHODOLOGY}

The focus of much of the existing research into burnout is aimed at individual workers, leaving a gap in the literature regarding what effective staff support entails (Curling and Simmons 2010). I wanted to learn if burnout/injury is a problem in the aid sector because the cause is systemic to the aid sector. Although most aid workers are people working in their own countries, I have focused my research on aid workers who are based abroad. To delve more deeply into the intersection of the experiences of international aid workers and the type of organizational support that would effectively lead to a healthier work environment, I set out to fill that gap and answer the following questions:

\section{Research Questions}

1. From the perspective of aid workers, in what ways does the organizational culture influence the prevalence and severity of burnout/injury symptoms that they experience? 2. What specific actions can aid organizations take to reduce the prevalence and severity of burnout/injury symptoms among their field-based staff?

\section{Design and Data Collection}

I conducted this research employing two qualitative methods and one quantitative method. The first qualitative method is an autoethnography detailing my personal reflections on my years in the aid sector. The other qualitative method involved conducting semi-structured interviews with internationally based aid workers. The quantitative method I used - although I had originally planned to conduct a scientific survey pre-COVID-19 - was an online poll of both 
headquarters and field-based aid workers from various international aid organizations. Below I explain each in more detail.

\section{Qualitative Method: Autoethnography}

Autoethnography is a qualitative research method described as "an approach to research and writing that seeks to describe and systematically analyze personal experience in order to understand cultural experience" (Ellis et al. 2001). Its intent "is to acknowledge the inextricable link between the personal and the cultural and to make room for nontraditional forms of inquiry and expression" (Wall 2006). My intent was to reflect deeply on my own rich experience as a humanitarian aid worker spanning over thirteen years in different countries, capacities, and contexts while acknowledging my bias and any preconceived notions I might have had. Staying aware of my hunch that poor management and organizational culture were the primary factors contributing to burnout and was careful not to create leading questions. In fact, this research drew me to a different conclusion as it revealed to me a more complex situation - one that in a sense presently holds aid organizations hostage almost as much as it does aid workers.

It was my personally traumatic experiences with burnout that inspired me to conduct this research, in part to rid myself of the demons. Ellis et al. described how writing an autoethnography can be perceived as therapeutic - that autoethnographers act as witnesses as they "not only work with others to validate the meaning of their pain, but also allow participants and readers to feel validated and/or better able to cope with or want to change their circumstances" (2001). This therapeutic aspect is a critique of this research method and there is "resistance to the intrusion of autobiographical approaches to knowledge production and sharing... and the researchers use of the subjective self' (Wall 2006). As I did not undertake aid 
work with the prior intention of conducting an autoethnography, I did not take notes at the time and instead relied heavily on my memory. My memories are of relatively traumatic and highly salient events, accounts of which I have shared with supervisors and colleagues over the years, and I am confident of their accuracy. The act of interviewing further helped me to recall and reflect upon various incidences that either mitigated or contributed to my burnout. My reflections are interwoven throughout the analysis, and I remained attentive both to how my own experience could influence my research process and how the data I collected might confirm and/or challenge my assumptions.

\section{Qualitative Method: Semi-Structured Reflexive Interviews}

Realizing that my own personal perceptions and epiphanies may not be shared by everyone equally and considering that the autoethnography is not without its criticism for being indulgent and narcissistic (Wall 2016), I conducted semi-structured, reflexive interviews to learn more from the burnout-related experiences of my aid worker colleagues. The value in this approach is defined below:

Reflexive, dyadic interviews focus on the interactively produced meanings and emotional dynamics of the interview itself. Though the focus is on the participant and her or his story, the words, thoughts, and feelings of the re searcher also are considered, e.g., personal motivation for doing a project, knowledge of the topics discussed, emotional responses to an interview, and ways in which the interviewer may have been changed by the process of interviewing (Ellis et al 2001).

With the explicit goal of understanding more about why burnout is so prevalent in the aid sector and what concrete actions can be taken to prevent or alleviate it, I created an Aid Worker Interview Guide (Appendix A) and interviewed individuals with extensive experience working internationally for humanitarian aid organizations. I was particularly interested in participants that had experienced at least one of the symptoms of burnout (emotional exhaustion, depersonalization, and/or lack of personal achievement) during their service. While I did not 
directly ask the participants to describe their burnout experience, wanting to avoid emotional topics and focus on the proximate causes instead, some still choose to share their vivid accounts.

Sample and participants: I recruited the participants from my personal contacts in Facebook and sent 22 invitations via Facebook messenger. The invitations included a brief personal message and the same script describing my thesis topic, the fact that I have personally burned out myself, and my intention to interview people who have worked internationally for a humanitarian aid organization and experienced the common symptoms of burnout. I assured them of the confidentiality of the interviews and emphasized that my end goal was to have actionable items to share with aid organizations to improve their staff wellness policies. Fifteen of those contacts responded, nine of whom were ultimately interviewed and three others who at first agreed but did not follow up after receiving further information such as the timeline for interviewing and the letter of consent. Two others were contacted via email with the same script and while both agreed to be interviewed, one ultimately was unable to due to personal matters. Because I originally had 12 interviews lined up and not wanting to bother people as we were in the middle of a pandemic that I knew left many particularly busy and stressed, I did not send follow up reminders to the seven contacts that did not respond to the first invitation.

Within a week I had scheduled most of the interviews and both men and women were excited to share their experiences and opinions with me. Some of the respondents knew each other well and one even recommended that I reach out to their friend who had already agreed to participate. Three of them who are particularly close spoke amongst themselves prior to the interviews, but all thoughts shared were those of the interviewee alone and their perspectives were quite different and did not mimic each other. A few of my contacts that did not choose to be interviewed also offered to or actually did send me the names of friends who might be interested, 
although that was ultimately not necessary as the data that I collected from the first ten participants began to reveal no new insights into the proximate causes of burnout.

In all, I interviewed five women and five men, all but one of whom are native English speakers originally from the United States, United Kingdom, Australia, and South America, and all but two of whom are non-Hispanic white. Each of the interviewees had from seven to 20 years of experience in the aid sector with one exception of approximately three years, and they worked in multiple contexts including conflict, natural disasters, and development. Some had both field and headquarters experience and others had worked as managers. Their experience and mine spanned across the world, from the United States and Europe to Latin America and the Caribbean, sub-Saharan Africa, the Middle East and Northern Africa, and Asia.

The interviews were conducted and recorded over Zoom and ranged from 38 to 149 minutes. All interviews were recorded and fully transcribed with the help of Otter. After each interview, I transcribed and uploaded it into MAXQDA where I coded the data and wrote analytic memos, searching specifically for information that pertained to the proximate causes of burnout, burnout as an injury, the emotions involved in aid work, and what can be done to prevent it. I have assigned each interviewee a set of initials to obscure identities and maintain confidentiality. Their demographic information and experience, along with mine - MQ - are outlined alphabetically in Appendix A.

\section{Quantitative method: Online Poll}

Although speaking at length with a group of individuals with over 200 years of direct personal experience in the aid sector was sure to give insight and perspective into the problem of burnout, I wanted to expand my source of information, especially as it pertains to my second 
applied research question - what specific actions can aid organizations take to reduce the prevalence and severity of burnout/injury symptoms among their staff? I therefore simultaneously conducted a brief online Aid Worker Poll (Appendix 2) in Qualtrics for both expatriate field-based staff and headquarters staff of humanitarian aid organizations directly implementing assistance projects in a country dealing with a natural disaster, conflict, or poverty.

In December 2020, I posted the poll on my personal LinkedIn and Facebook pages, as well as on a Humanitarian Aid Worker Facebook page - Fifty Shades of Aid or 50SOA - that has over 25,000 members. The invitation to take my poll explained that my thesis was on aid worker burnout and that I was primarily interested in the kind of support aid workers would like to see their hiring organizations offer. While there was no stipulation that they must have suffered from the symptoms of burnout to take the poll, it is almost certain that those who had were more motivated to click the link than those who had not.

In January 2021, I reposted it on my personal LinkedIn and Facebook pages. When I closed it on April 5, 2021, 103 people had clicked on the link, of which 99 answered the questions. Having seen on 50SOA that aid workers were complaining about how many surveys they had been asked to take during the height of the COVID-19 pandemic and seeing that my poll was closely followed by two other questionnaires, I refrained from asking them to repost the poll and anticipated a small number of completed responses. In fact, not wanting to exacerbate the stress that aid workers were already under, I had streamlined my original lengthier questionnaire and used an abridged version focused primarily on my second research question. I included the key open-ended question, "If you were put in charge of writing your organization's staff wellness policy, what would you include to prevent or alleviate international staff burnout?" 
In doing this I gathered important data about what aid workers think organizations can do to better address burnout.

Ultimately, 99 aid workers completed the descriptive poll which I analyzed in Qualtrics. Of the respondents, $24.2 \%$ reported having worked in the humanitarian aid field between $1-4$ years, $27.2 \%$ between $5-9$ years, $21.2 \%$ between $10-14$ years, and $27.2 \%$ for 15 or more years. A majority (53.5\%) had been stationed exclusively at international duty stations, $42.4 \%$ worked both internationally and at their organization's headquarters, and only $4.0 \%$ reported having worked exclusively at headquarters. This response cumulatively represents hundreds of people-years spent in the aid sector, in both the field and headquarters. These data serve to identify what measures aid organizations can take to prevent or alleviate burnout in their staff. I integrated the data from the poll and interviews and present them in the policy implications section. 


\section{CHAPTER IV: RESEARCH FINDINGS}

I conducted this study to answer two research questions - how organizational culture influences the prevalence of burnout/injury symptoms and what specific actions can aid organizations take to reduce the prevalence and severity of burnout symptoms among their internationally-based staff? I reflected at length on my own personal experiences, interviewed ten aid workers, and conducted a poll on burnout and organizational practices. The poll attracted primarily (96\%) respondents who had experienced burnout themselves, almost half (48\%) describing their worst case as "severe." As described in the methods section, this selection bias was not unexpected as those who have burned out are likely highly motivated to discuss the issue. In the section below I address my first research question - how does the organizational culture influence burnout?

\section{The Very Nature of The Aid Sector Increases Burnout among Staff}

"[The aid sector is] set up for failure" - CN, referring to employee burnout

Although I embarked on this research with an expectation that aid organizations are a primary factor in the high rate of aid worker burnout - and I was not entirely wrong in that expectation - my findings point to a much larger problem. Aid organizations exist within a problematic sector and are not wholly responsible for the pressures they can place on their staff. When asked what specifically aid organizations could do to reduce burnout, several interviewees described instead how the aid sector itself was set up in such a way that there was little that individual organizations, much less individual aid workers, could effectively do. It was, in effect, a systemic problem, one that was "set up for failure." 
The aid sector is highly competitive with a mismatch between the number of donor agencies and aid organizations. A glut of aid organizations working on any one response forces all of them to engage in burdensome coordination efforts. Aid work is subject to the unpredictable whims of natural and human-made disasters and conflicts requiring an immediate response as well as a relatively - in comparison to other employment sectors - limited period of time to address. These factors lead to the creation of an excessive workload well-known for bringing about both physical and mental health problems.

Furthermore, the unavoidable security issues that are part and parcel of many humanitarian aid assignments further contribute to the stress that increases both the prevalence and severity of the symptoms of burnout. Finally, the competitive nature along with the oftentimes macho, sexist atmosphere and the stigma around mental health issues combine in such a way as to decrease the amount of support aid organizations might offer and make aid workers reluctant to seek help - or even recognize that they may need help. Below I expand upon each of these concepts that will explain how the proximate cause of aid worker burnout is ultimately the aid sector itself.

\section{Excessive Workloads Devastate Mental and Physical Health}

“Something changed in me that I can't get back." - SD

Overworking can have long term effects on a person's health, career, and quality of life. It is not just a matter of taking time off to recuperate and bounce back; the stressors that lead to burnout — particularly those associated with excessive workloads — can also lead to poor physical health, including increased rates of disease and death (Michie and Cockcroft 1996). My findings 
lend further support to that research. For example, $\mathrm{CN}$ described the negative impact of working in the aid sector as having "taken years off my life and probably taken a toll on my relationships and my health" and SD experienced so much trauma on her first overseas assignment that it was close to a year afterwards before she could even say the name of the country without crying. She went from being a prolific reader and writer to someone who has struggled to read a book since, even now many years later. She bleakly told me, "Something changed in me that I can't get back."

Furthermore, KE ended up with both physical and mental manifestations of the burnout she experienced over the course of years working in conflict zones. She now suffers from vestibular migraines on a regular basis that can last for well over a week and ear issues that make her feel dizzy and unable to fly, as well as permanent brain fog. A highly educated woman who was not only hard-working but fearless, KE can no longer physically or mentally perform aid work and was forced to retire at a relatively young age. She described her debilitating symptoms as, "The brain fog is pretty permanent right now. There's this gray haze over me that I can almost not break through anymore. It's a nightmare. It's a total nightmare. I used to be a smart lady, but not anymore." Finally, my own most terrifying experience with burnout was when I suffered from repeated attacks of paralysis described above, which occurred after my manager denied my home leave, reneged on a previously made job offer/contract extension, and then crammed my suddenly final two weeks on assignment with additional work - his work. 


\section{Excessive Workloads Are the Primary Culprit Regarding Burnout}

“The workload was insane." - $\mathrm{PH}$

Nine of the ten interviewees reported excessive workloads as a normal part of their humanitarian aid experience - a frequent occurrence if not chronic - and many of them believed it was a primary trigger of their burnout. The tenth was a manager who recommended delegating tasks to the rest of the team to avoid overworking. Interestingly, another interviewee reported to this manager and burned out under his command. The rest of the respondents described working 16 to 20 hours a day, six or seven days a week, forgoing holidays and earned personal time off (PTO) for extended periods of time - sometimes for years. VH burned out due to a workload she described as "nonstop" even as her motivation to do the work stayed high. She believed it would not have been possible to do it if she had had a family at the time and said of her organization, “They're asking you to work your life away when you do that kind of work." DS described working 20-hour days, "working nonstop every day till the break of dawn on constant deadlines.” PH described an occasion when her boss tried to assist her by purchasing unprescribed medication for her in recognition that her workload was so excessive that it could not be naturally sustained for a long period of time:

The workload was insane. We were working 16-hour days and my boss took me to one of these dispensaries in (country of assignment) where you can buy any kind of medication. And he bought a bottle of Valium for me and said, "You just need to take one of these a day and you'll be able to keep up the 16hour-a-day workload. There's no other way.

While other interviewees did not share stories about their managers purchasing them medicine that is only available by prescription in the United States, PH's story implies strongly that her manager himself took Valium to keep up with his own 16-hour a day workload and found it an effective enough coping mechanism to recommend. During one assignment when I 
worked briefly with PH, I told her that I had been having trouble sleeping and she quickly handed over a plastic bag of two kinds of sleeping pills that she kept for plane rides, which I happily accepted. This speaks to both of our willingness to prioritize our work performance and meeting expectations, even at the cost of our physical and mental health, in the face of an unreasonable workload.

The workload can be so intense that the additional time off known as rest and relaxation (R\&R) offered by most aid organizations for hardship positions amount to small or no relief. SD shared how, when in a highly technical position that could not be covered by colleagues, she was unable to truly unwind and disassociate from work:

R\&R was a joke, because I got anywhere from 100 to 150 emails a day. I had to check my mail. I didn't respond, but I had to weed them out and file them and mark what had to be done.

A senior manager, RS, acknowledged that one could easily work "many, many, many, many hours without end," essentially working themself "to death," but recommended putting up limits on your work schedule or delegating tasks as a solution. My findings, however, indicate that such an approach, while perhaps possible for senior management, would be much more difficult for project staff who are expected to complete their work successfully and submit their reports on time with few complaints if they want to stay employed in the sector. Below I explain why aid workers are often forced to take on more work than one person can reasonably manage. 
Flowchart 1. The aid sector is competitive and donor-dependent

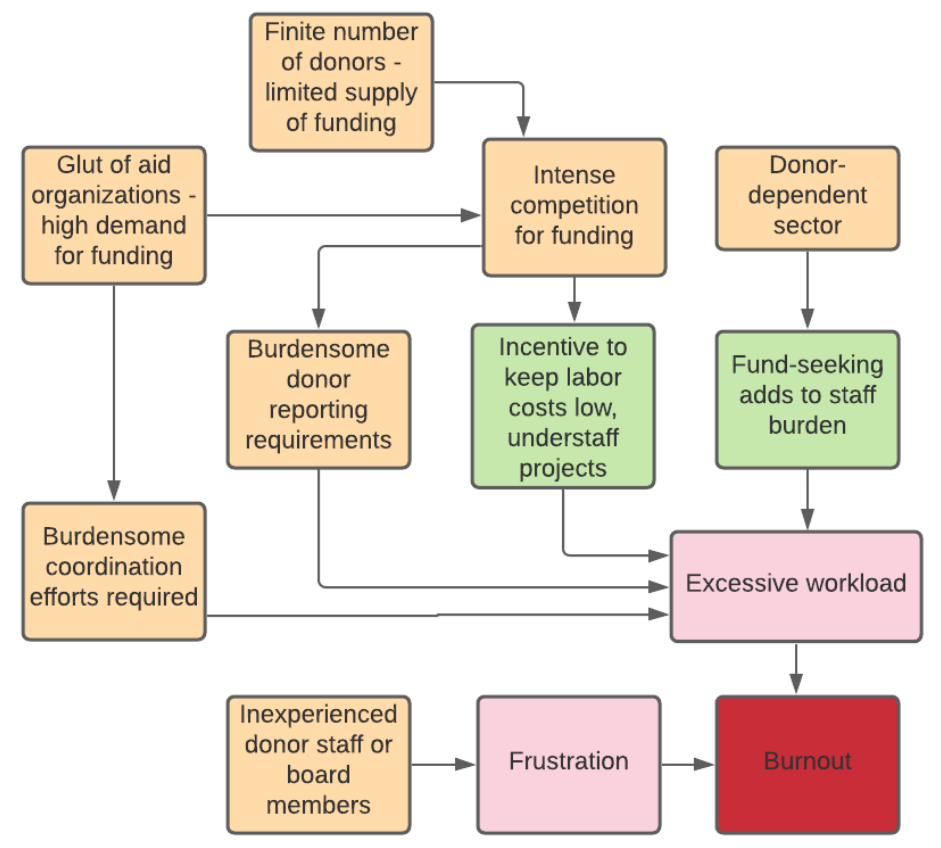

Aid Sector

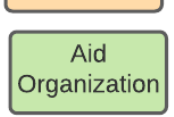

Burnout trigger

\section{Competitive Nature and Focus on Growth}

The humanitarian aid sector, existing as it does within a competitive system, is both subject to the laws of supply and demand and focused on growth and expansion. As OF pointed out, many donors are capitalist agencies or large consultancies that exist primarily for their own self-interests and some of the largest donors, such as the World Bank or the Asian Development Bank, are "giant economic enterprises with political agendas." Additionally, there is a finite number of donors and resources available but a virtual glut of individual aid organizations vying for those resources - just shy of 10,000 international aid organizations in the United States alone (CauseIQ 2021). CN explained that almost all aid organizations are completely or predominately grant-based, with everyone's jobs, from HQ to the field, contingent on their ability to successfully obtain a grant. As donors, governments, private organizations, and taxpayers pressure aid organizations to be more efficient and eliminate anything deemed wasteful to stay 
competitive, labor-associated costs suffer - as does actual labor. $\mathrm{CN}$ reflected below on the additional burdens of grant-writing:

Can you imagine writing a competitive proposal and writing in psychosocial support for the staff implementing it? Right, like, you can barely get it for the beneficiaries who are being bombed on a daily basis. Can you imagine asking for that, for the staff of the organization that's receiving the grant? You'd be laughed out.... [The aid sector] is set up for failure in terms of making sure that staff have adequate resources, are not overburdened, are not overstressed, are not feeling like they're about to burn out. And I feel very strongly about that.

This intensely competitive nature and, as described by IN, "incessant emphasis on growth and expansion," dehumanizes aid workers by expecting ever more work in less time with fewer resources and almost no resources earmarked for mental health. RS further explains that donors will not accept budgets with too high a ratio between salaries/benefits and direct services, because "if the donor agency does, then later an evaluation is published saying that only $\mathrm{XX} \%$ of the money went to the people that the program was trying to help, and all hell breaks loose. You never win."

\section{Donor-Dependency}

The burden of donor dependency is such that already overworked staff must then spend time seeking resources for their next project, essentially forcing them to work double-duty writing concept notes or proposals while simultaneously implementing their present project. This includes senior management as RW explained, "If you're the country director for Save the Children or for CRS, or for Mercy Corps, you're expected to bring in money." IN described this as a very stressful process like "asking somebody to design their own car, build it, and run it all at the same time." Even if a specialist is hired as a proposal-writer, a great deal of time and input is still required from the project staff. As $\mathrm{CN}$ explained:

Not only are you trying to execute the grant that you have, but you're trying to get more grants. So, you're busting your ass to fulfill the timeline that you're on for the current grant while also expected to provide 
inputs or perhaps even write a full proposal on your own for additional grants. I mean, that's a set up for failure. That's a set up for burnout.

Additionally, VH explained how program funds are set on yearly budgets so there is pressure to spend all the funding by the last quarter - no small task in complex emergencies - for fear that their budget would be otherwise decreased. This leads to a "big scramble" of activities towards the end of the program as everyone rushes to spend money.

\section{Burdensome Reporting Requirements}

Donors often have strict and burdensome reporting requirements that organizations are forced to comply with - requirements that vary from one to another and divert time and attention from program implementation. Organizations must then have their already overworked staff spend time keeping track of different reporting formats and completing long, detailed reports. A friend from another organization once told me he warned his colleague to put a full-time reporting officer in their grant proposal to my organization because our reporting requirements were so extensive. These burdensome requirements, even with the best of intentions, reflect a distrust of the host country nationals and are used to justify hiring expatriate staff. OF explains how this happened in his case responding to a particularly large disaster regarding the terms of references that were written by "international experts":

They have this formulaic way for terms of reference for World Bank projects which perpetuates employment of a 'club' of international experts experienced in doing business under these terms of references. It's to do with due diligence and to make sure that a whole bunch of western style humanitarian and human rights type things are covered, and corruption is sort of minimized. And there's engineering excellence, and so forth, that was all written in this giant terms of reference. I had to end up doing a lot of the work because the reports - an extraordinarily large number of them and many were very lengthy and complex addressing the terms of reference - had to be written in English to a World Bank standard. 


\section{Burdensome Coordination Efforts Required}

The glut of organizations vying for and receiving funding from various donors for the same region also necessitates frequent coordination to ensure proper program coverage and avoid overlap of project areas and activities. Although recognized as essential, and rightly so, coordination meetings take time and energy away from the project activities that an aid worker is already under pressure to perform satisfactorily. Coordination is also a concept that is more difficult to do well than one might first imagine, as there are competing organizations that must work together to avoid duplication, each with its own set of requirements. OF described how the presence of different international NGOs with their own driven agenda and urgency to act quickly can lead to problems: "Sometimes they're actually fighting each other for the right to build this or build that. This is what was going on in our zone because everything was happening so fast. I mean, there were examples where two community centers were built for the one community."

\section{Inexperienced or Uncommitted Donor Staff Increase Frustration}

Donor agencies and members of their boards are not typically experts in humanitarian aid, although that does not always preclude them from assuming a technical role. This leads to unnecessary complications of otherwise common problems with straightforward solutions. VH discussed her annoyance when dealing with a government donor agency whose staff had varying technical abilities, some of whom seemed to "make up stuff just to be cutting edge." As she explained it, "None of this is cutting edge. Not the real needs. It's boring, it's a pyramid. They need to know how to grow their food, they need healthcare, they need psychological support." 
Donor staff are not always committed to the principles of sound humanitarian practices and are less likely to insist upon finding community-driven, sustainable, and environmentally sound solutions. This flies in the face of all the training that aid workers receive and can be a great source of frustration for those who care about getting long-term positive results in a dignified manner for the people they serve. $\mathrm{CC}$ and $\mathrm{KE}$ both expressed this kind of frustration with donors who apparently prioritized receiving a completed report and who were inflexible when fieldbased staff recommended changes. $\mathrm{CC}$ asserted that some implementing organizations' donors do not want exceptional programs or even efficient ones, explaining further that, "They don't necessarily want efficient programs, they are often more concerned with their 'burn rate,' how quickly they can spend money to get more overhead. They want programs that don't raise questions and meet the TOR (Terms of Reference)." KE recalled one particularly inflexible donor who insisted on following the project plan as written regardless of surprises in the field:

I don't necessarily know that there's an over-arching objective so much as there is, "We want to see this happen and we don't care how it gets done. We're gonna do this, and we're going to do that and we don't care if this messes you up, or that messes you up. We're gonna do it anyway because we have our objective." Anyway. So then, after that is when my health started to crash.

In this interview excerpt, $\mathrm{KE}$ describes how her desire to implement effective programming was frustrated by the donor's inflexibility and how that frustration led to the deterioration of her mental health. 
The Nature of Disaster and Conflict Response Increases Burnout/Injury

Flowchart 2. The aid sector is disaster and conflict-driven and therefore unpredictable and unreliable

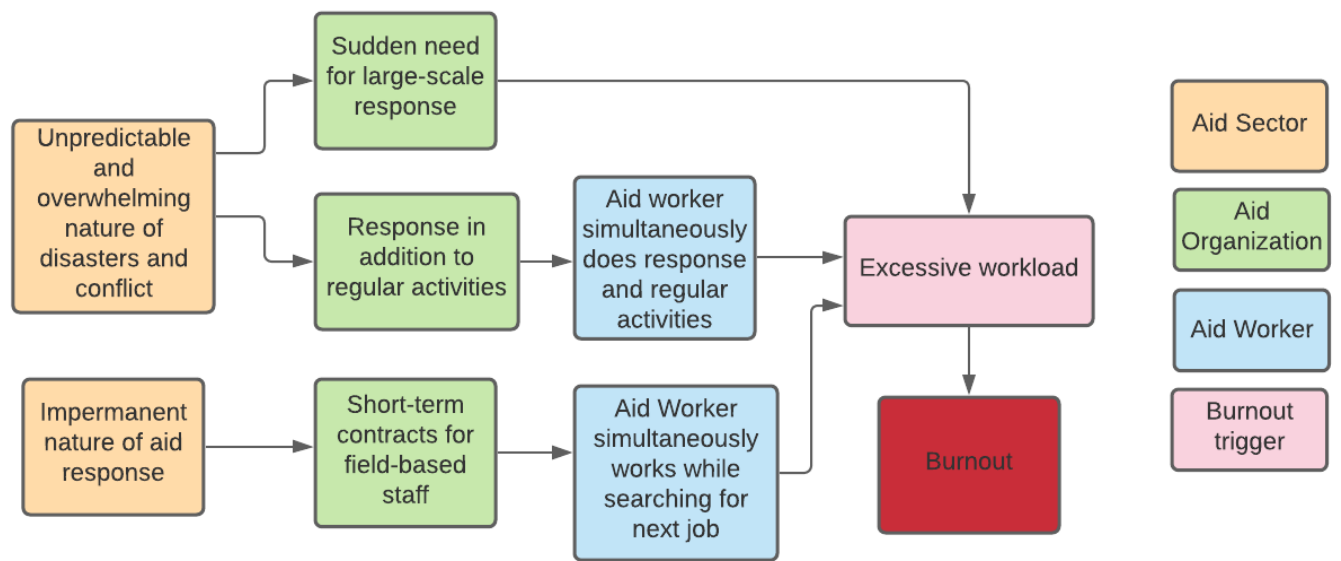

\section{Unpredictable and Overwhelming Need}

The aid sector is unpredictable and often at the whim of nature and political actors as disasters strike and conflicts break out without much warning. The nature of an immediate disaster response can be overwhelming in its rush to provide lifesaving food and non-food items, perform needs assessments to ensure a high-quality longer-term recovery phase, design programs, and request funding. Winning grants and contracts comes with its own set of complications. IN describes the problems stemming from unexpected funding windfalls and how these problems exacerbate burnout:

So, what contributed to the burnout? Well, there was a lot of money. One organization received a lot of money, more than it ever received before. It didn't have the capacity or the institutional knowledge to know how to manage that volume and then spread it out, you know, to the various country offices. And what that meant was that we're scrambling, and when they're scrambling decisions are made. With one organization that I'm thinking of, I was holding two to three positions that I was not equipped to manage effectively.

When I shared with CN that I did not feel personally cut out for the intensity of an immediate disaster response but considered myself more of a long-term recovery worker, he described his revelation that long-term recovery aid workers may in fact have it worse than first 
responders as they often work the same long hours with fewer hardship benefits. He described how first-responders "parachute in" and work around the clock for a short period of time, thus setting the bar of working long hours for sometimes years to come. The longer-term recovery workers follow first responders once the electricity and water access are restored; thus, they feel shamed into unsustainably long workdays. As CN put it, "It's like, how dare you complain?"

\section{Impermanent Nature of Aid Work}

Unlike other industries, the aid sector is designed to address immediate needs over short time-horizons. Field staff, therefore, operate on short-term contracts from three to twelve months in most cases. As CC put it: "development work is much more of a gig economy," in which aid organizations do not actively discuss long-term career trajectories with their employees. This precarity is justified as ethically necessary as it would be unethical to draw out a disaster response deliberately and unnecessarily when people are in desperate need. Effective development builds local capacity to avoid perpetuating dependency, and aid workers understand short-term contracts as ensuring project sustainability. Aid workers, as a result, spend a disproportionate amount of time searching for jobs. This harms the aid worker but serves the organization, mitigating the effects of burnout with frequent turnover. 


\section{The Aid Sector's Inherent Insecurity Increases Burnout}

Flowchart 3. Inherent insecurity and restricted movement of staff

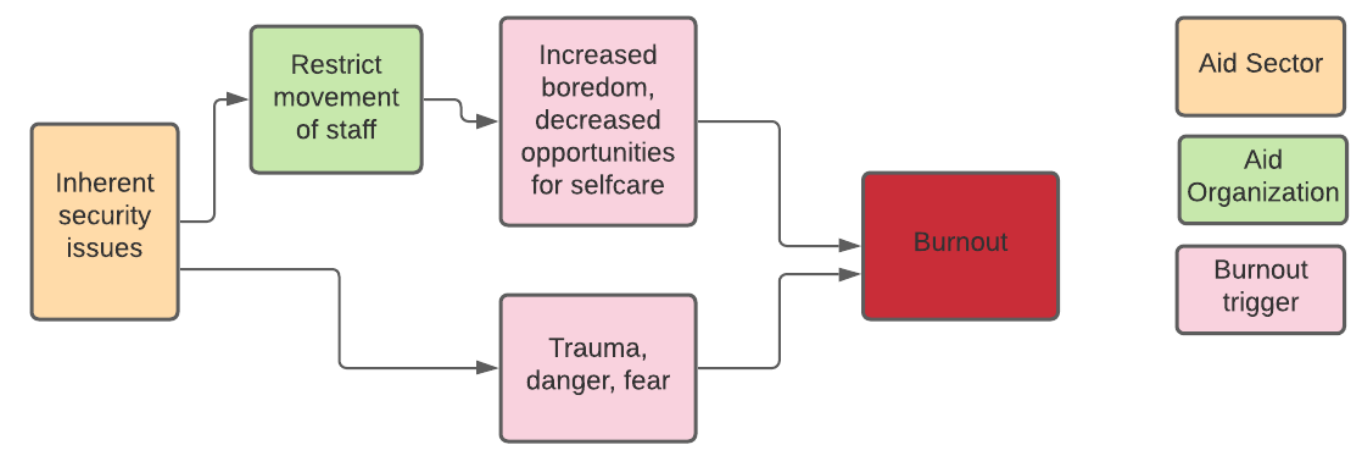

\section{Security Issues}

Disasters and conflicts can create security issues and frustrations for field staff. Research participants with experience in both disaster and conflict zones concurred that conflict work is more likely than is disaster work to result in burnout. KE described conflict work as "a completely different animal" than disaster response because "conflict zones have actual people working against you." She characterizes the fear and emotional toll of working in two different conflict zones:

The opposition group just rode right through the middle on horseback and killed and took down a whole bunch of tents and left a whole bunch of people dead, and just shot up a lot of people and set a whole bunch of things on fire. And even from my perspective, when you do the assessment of that afterwards, and you just want to sit down a while after throwing up, you just want to cry. Because what, why, what is the point? And then, (different conflict zone.) Story after story after story. We were supporting a hospital on the [other] side for these people who came over with gunshot wounds - children and women. And, you know, why? Why are you shooting children? Why are you shooting children? And it's just, and that's when I really started being like, I just I can't do conflict anymore. I just can't.

SD described a particular incident in one conflict zone that was so harrowing that the aid workers were temporarily evacuated, and many of them refused to return to their assignment right away.

All hell breaks loose. Massive fighting. Fighting goes on for five days, five days of hardcore missiles stuff. We are all sitting in our safe room, which is not a safe room at all. There's no bolt on the door, they can easily break it down. So, what happens on the fifth day, there was a peace, okay, everyone's fine. There's hundreds of dead bodies out on the other side of that wall, hundreds, hundreds. Some of us volunteered to 
put bodies in body bags. Some of those people were dead for five days, and here we are picking them up and zipping them up. A lot of people didn't come back to (country of assignment) for quite some time only because of the insecurity... because that was too hard for them.

The physical and mental trauma and fear of death that accompanies this work weigh heavily on aid workers. And while managers may also fear for the safety of their employees, they nevertheless expect them to ride out difficult assignments with little complaint since security risks are an inevitable part of the work that aid workers knowingly assume. Organizations often bolster mental health care immediately after a security incident, but in general mental health is de-emphasized. SD described rarely feeling safe in her first assignment. During her commute one that could take upwards of four hours depending on traffic - she and her colleagues were attacked and robbed, their vehicle was tipped over, and their car windows were bashed in. The roads were so unsafe they often drove past the bodies of people hit by cars. This went on for two years.

Although aid workers themselves suffer from constant threat of security incidents, they are also burdened with the task of keeping their local staff safe. $\mathrm{CN}$ shared how, as bad as it was for him, he was even more concerned with his local employees for whose safety he was responsible:

I also didn't sleep very well, because at night there was shelling. Our neighborhood was shelled, I was caught in some crossfires, our office was closed, we had to relocate the office to several locations. If something happened to myself or any of my international staff, it was usually 'wrong place, wrong time.' What caused much more stress for me, and much more anxiety, was the fact that the national staff were at much more risk, had families, and I was responsible for decisions of placing them in potentially very, very great harm, you know, injury, death, kidnapping, all of those things.

One does not need to witness streets littered with corpses to feel debilitated by stress. Second-hand stories of security incidents can also provoke distress. During the first five months of my assignment in Nairobi, Kenya, five acquaintances of mine were car-jacked and robbed, which provoked my own alarm and anxiety over the possibility. Also in Nairobi, a research participant was warned by a hotel worker that she must take a taxi to her destination rather than 
walk "or you'll arrive there naked." Second-hand security incidents and warnings produce a state of alertness and wariness in aid workers that depletes one's psychic energy and takes a toll on one's well-being.

\section{Restricted Movement of Staff}

The death or physical harm of an employee would expose an aid organization to liability issues and damage both the organization's ability to continue to provide programming and its reputation as safe and reliable. They can therefore sometimes take excessive measures to restrict staff movement in the interests of safety without necessarily considering the effects such restrictions can have on mental health. RS, who was a manager in several countries over the course of 20 years, explained it best: "I think they get carried away, but the consequences of an incident are huge. They paralyze your country office. So that's the problem. The nightmare is that somebody gets kidnapped or murdered." These restrictions, however, not only increase the feeling of being surrounded by danger, but they also make it harder for staff to engage in selfcare behaviors such as socializing with friends or going out to dance, and movement restrictions can lead to boredom, lack of privacy, and additional stress. I often describe my last assignment, where I had shared accommodations and our every move was monitored for safety reasons, as making me feel like a lab rat under constant surveillance. It did not bode well for my ability to stave off burnout. 


\section{The Aid Sector Increases Reluctance to Seek Mental Health Assistance}

Flowchart 4. Aid sector factors causing reluctance or delay in seeking help

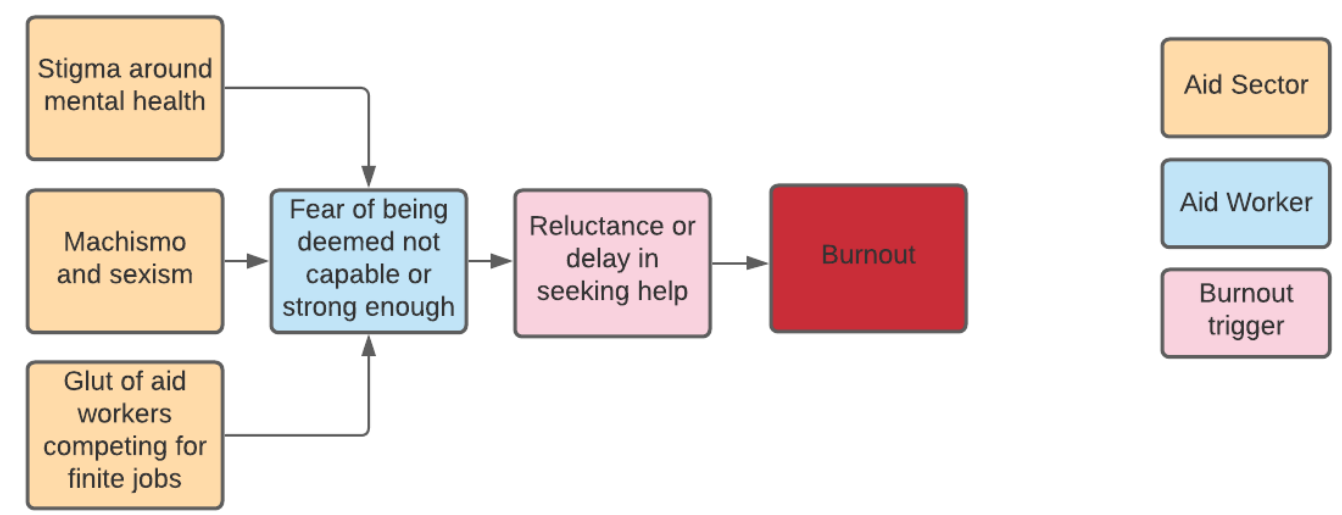

\section{Stigma}

The stigma around mental health issues is at least as widespread and problematic in the aid sector as it is in the general population of the main donor countries. This creates an environment where people are naturally reluctant to discuss their mental health or openly seek help. The Employee Assistance Programs (EAP) offer confidential mental health counseling. However, even when organizations offer these resources, they are rarely used because aid workers consider these services ineffective or doubt their confidentiality. Aid workers especially at the entry-level - worry that merely admitting to mental health issues will stigmatize them as weak and negatively affect their reputation and ability to get another job in the sector. Like SD, who reported behaving in such a way that no one would have ever known that she was miserable, aid workers hide their true feelings and refrain from asking for help. CN sums up how mental health stigma combined with the small, insular world of aid work prevents people from seeking assistance when they experience the symptoms of burnout or other problems:

There's definitely a stigma. I mean, word travels very fast. This is a very tight group of people, so when someone loses their shit, or some problem happens, or someone gets pregnant, or someone has a drug or drinking problem, this goes around the circle very, very quickly. And quite frankly, the humanitarian business so incestuous, it's very nepotistic, and that spreads to the donors. So, heaven forbid you're trying 
desperately to keep jobs for the people that you employ, to keep grants going to help the people you're trying to assist, and somebody hears that the country director, or the program manager, or the director of programs, or the operations manager, has some problem is seeking psychological help. I mean, that's a big deal. That's a huge deal. And you would never want that to get out into the community. So there definitely is a stigma.

Without such a stigma, aid organizations would offer greater mental health resources and workers would utilize them more readily. DS described how in one country where he was assigned, there was a massage therapist who offered to give aid workers free massages as part of her outreach to address stress. Because there was no stigma attached to massages, no "you're crazy or anything like that," he and his colleagues happily queued up. KE described how immediately after a colleague was shot, counseling sessions were offered with a promise that it would not damage their career.

When a colleague got shot in the face and lost an eye, they had psychologists and psychiatrists available to us, they had a 24-hour phone number available to us. They also made sure that for that specific timeframe if we made use of any of those services it would not count against us. You know how when you work for the (government donor agency) if you see a psychiatrist, sometimes it dings against you - 'Oh, you've seen a psychiatrist, we're not sure we can recommend you going overseas.'

This account exemplifies how stigma around mental health persists in the aid sector and that even when there is a reprieve from that stigma, it is for a limited time only. I believe that stigma would lessen if burnout were considered an injury instead of a personal shortcoming.

\section{Machismo and Sexism}

The widespread perception of machismo and sexism permeates the aid sector. White men from Western countries founded and continue to influence the institutional culture of competitiveness, long work hours, and stoicism and "strength." IN elaborates on the pervasive ideal of machismo in the sector and links it to her own struggles through the sense of guilt that machismo generates in those unable to maintain the façade:

It's very machismo - and when I say that is the male archetype, it doesn't have to be a male, I have met females that are equally as tough, you know. So, it isn't just about a gendered thing, you know, like male or sex thing, male, female. But it's taken a while for me to understand that my recovery did not go as well as it 
could have, because somewhere along the line, I felt that it was my fault that I got sick while I was working really hard, and that I still hadn't performed, and people were very unhappy with the way that things had gone.

The "machista" characteristics of the aid industry are problematic for all aid workers but disproportionately hurt female staff. Women who take on the male-archetype can leave their staff frustrated by failing to show empathy. PH, for example, described one female boss who thwarted her efforts to assist a family in need, as "tough" and "a cold-hearted bitch" and decided she would never work for her again. Two of the times that I personally experienced burnout were under female supervisors with male-archetype attitudes. The first of these supervisors was known for working very long hours herself and expecting the same from her staff. She once expressed deep disappointment that I did not cancel a Thanksgiving vacation with my family who I saw only once a year - to attend a training that was organized after my travel plans were made. The second one deliberately tried to make anyone who did not rise to her standards feel miserable and powerless until they quit. She explicitly revealed this philosophy to me as managerial advice when I was dealing with an uncooperative program manager. She even offered to "ice her out" for me. For these reasons, I recognized the pattern when she eventually did the same to me.

Many female aid workers just accept the sexism as the way things are, even when it directly affects them, rather than calling attention to themselves by fighting it. SD talked about seeing many instances of sexual harassment from the men at her duty station but did not press the issue as she was excited to be there. Additionally, women's health issues, even severe cases, are downplayed or go unsupported even when the women ask for help. In one instance, an offer of contract extension was withdrawn after I refused to forgo my home leave due to tachycardia and insomnia. This incident taught me to never again share any kind of physical or mental weakness with management. Female interviewees also describe similarly frustrating experiences 
of sexism, such as $\mathrm{PH}$, who worked with male colleagues in Thailand, a country known for its sex tourism:

I was in a meeting, and I was the only woman in the management team, and they said, 'Okay, we're gonna go out for our meeting." And it was basically in (the neighborhood), you know, where all the sex workers were. And so that's what we did. We went to a ping pong bar, and they watched girls shoot ping pong out of various parts of their body while we had our work meeting. That was their stress relief, that made me more stressed if anything, - so inappropriate. But and that's the thing. I think women have a harder time because a lot of the cultures that we work in women are treated worse. And then the male colleagues that are with us that are held to a certain standard, they can relax those once we're no longer at the office. However, I continue to be a woman when I leave office. So, it's another level of stress.

SD discussed how she suffered from several bleeding episodes that were very frightening

to her, although she did not at first share her condition with anyone. She finally sought assistance from the male medical doctor working in her organization's Staff Health department:

I was freaking out in (country of assignment) because I felt I was over my head - the beginning was really rough. I would just bleed like crazy. And so that prompted me to go to the [organization's staff] doctor. And he's like, 'Oh, it's just probably menopause.' I'm like, 'This ain't menopause.' Like, where is it a symptom of menopause, bleeding? And he just poo-pooed me. I felt he wasn't listening to me. Because if I'm going to a doctor, it's because I can't figure this shit out. So anyway, I go to Dubai, and I have emergency surgery the next day.

Here SD described a situation where the one person clearly tasked with staff well-being outright

dismissed her symptoms and concerns. Worse, it turned out she was right to be concerned and in fact needed prompt medical attention. The macho, cavalier attitude of many men and some women in the aid sector make everyone worse off both physically and mentally.

\section{Competitive Nature of the Aid Sector}

Finally, the fact that there is a glut of aid workers competing for a limited number of aid jobs creates a highly competitive atmosphere that, coupled with the short-term nature of contracts, serves to increase the fear of being deemed not tough enough to find another aid job, which further exacerbates reluctance or delay in help-seeking behavior. It also increases the likelihood that one would stay in a stressful job that they would prefer to quit. As CN put it, "Of 
course, the fear is always there. If you're a Country Director, and you only last one year, what does that look like on your resume?"

\section{Poor Management and Organizational Practices}

Flowchart 5. Poor management and organizational practices contributing to burnout/injury

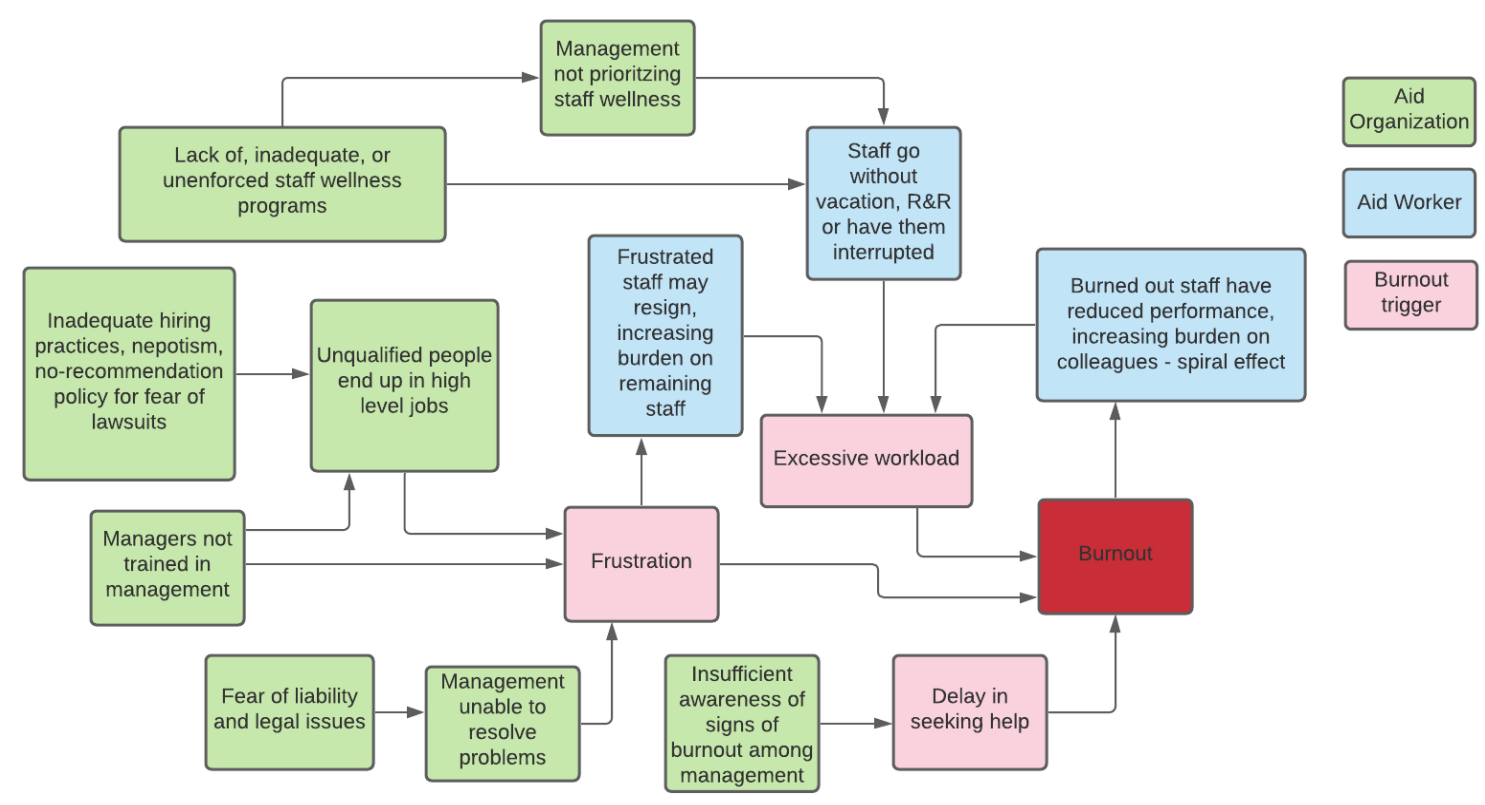

\section{Management Unable to Resolve Burnout-Related Issues}

Headquarters (HQ) staff and management are unable to offer effective solutions to burnout/injury because of both the demands of the job and their inability to understand the realities of field work. HQ staff are under the same competitive pressures to perform and please donors as international staff. But some HQ staff have never worked internationally, or perhaps not in the country or region to which they are now assigned, and that can mean, as $\mathrm{CN}$ described, that HQ staff can be "completely disconnected from the reality that you're experiencing 
managing field operations." He continued by counseling aid workers to not even speak to HQ staff, "because not only will they not help the situation, they will actually make the situation worse." CC corroborated CN's perspective observing that management did not want to hear about problems and that "the only ones who have any power in this dynamic whatsoever are the donors." He further observed how colleagues can "quickly fade into obscurity" after honestly sharing their failures. This culture of punishing perceived weakness denies workers the opportunity to learn from their mistakes and therefore increases the chances that those same errors will be repeated.

Aid workers identify the problem but do not place the blame directly on management, as

\section{CN elaborates:}

There's not much that they can do about it, quite frankly, they're not going to suddenly give you less hours, they're not going to reduce the grant that you manage, they're not going to change the deadlines that are pretty much set in stone. I mean, complaining to them would probably not serve any other purpose than reducing their confidence in the job that I was doing.

$\mathrm{CN}$ further characterized the propensity for burnout/injury in the aid industry as an inherent

problem, "baked in" to the nature of the sector.

I can give somebody the afternoon off. I can take a week and do a staff retreat. I could even maybe find the resources to squeeze some sort of psychosocial support person to do that, maybe. But at the end of the day, those deadlines and the fact that we don't have enough staff to do what's required of that grant, and hopefully chase the next grant that comes after that - that doesn't change. If I send that person home, it just means somebody else is gonna have to pick up the slack, or what usually happens is they have an even tighter deadline the next day when they come back.

$\mathrm{CC}$ and $\mathrm{CN}$ highlight the problem that even those in management with the best of intentions will have structural and practical issues that they are unable to overcome. In fact, they are often under the same pressures to work long hours that is so damaging to their own well-being. 


\section{Management Not Perceived to Prioritize Staff Wellness}

The general perception of aid workers is that organizations do not take staff well-being seriously. This was certainly the perception I had in my organization and is in large part what prompted me to conduct this study. It is further borne out by both the quantitative and qualitative aspects of this research. When asked, "Overall, how seriously would you say your organization takes staff wellness, particularly around mental health issues and the prevention of burnout?" $75 \%$ of poll respondents indicated that management did not take staff wellness seriously all or only slightly seriously. Just over a quarter indicated that their organization took staff wellness even moderately seriously.

Even when they do take measures to support their field-based staff, those measures are deemed ineffective. Seventy percent of respondents indicated that their organizations offered free employee counseling, but $66 \%$ of these considered such services relatively ineffective at reducing stress. Just six percent of respondents who reported receiving counseling thought it was very effective, while $68 \%$ considered it only slightly effective or not effective at all.

Aid workers, for the most part, feel neither comfortable nor hopeful discussing wellness with their manager or HQ staff. KE, for example, articulated feeling unsafe talking to her boss when she began to experience problems: "I only felt safe enough to talk to a few colleagues about it. Never anybody higher up. Because I never really felt like they were interested, would offer actual solutions. The response usually is, you know, 'suck it up."”

In my case, my managers outright denied my requests for help. When I told an HQ program officer that I could not physically make a deadline for a proposal after having worked 20 hours a day for two weeks, she responded by saying, "I have every faith in you, I know you can do this." Pep-talk platitudes replace actual support and solutions. I did, in fact, complete the 
assignment, but at what cost? This was the time my hair fell out, I feared falling asleep behind the steering wheel of a car, and it took several weeks for my sleep cycle to get back to normal. I never asked her for help again.

In another instance, both the HQ staff and field management told my colleagues and me that any complaint receive an automatic, "Maybe (country of assignment) is not for you." The message that HQ does not care about mental health is loud and clear and has real consequences. That country office had one of the highest burnout and turnover rates I had experienced in my career. One co-worker, who was truly miserable, packed all her belongings before her R\&R, took her trip as planned, and then resigned from abroad without ever returning to the country. It was on this assignment that I took up cigarettes as a very ineffective coping mechanism, chainsmoking in the wee hours of the morning to deal with insomnia.

PH shared two stories emblematic of the aid culture of stoicism and sidelining mental health concerns.

I remember sitting at my desk and just sobbing - sobbing loudly! And everybody around me was preparing to do the mental health resolution for the (aid organization). So, think about the irony of that. Nobody paid any attention to me. I'm sad. I'm like sobbing loudly and they're all running around me making photocopies, 'Oh, we got to do this for the mental health resolution.' And after literally 45 minutes, I thought this so fucked up and I just took my coat and I walked to the GP's office, and I got month's leave for burnout.

In the above excerpt, $\mathrm{PH}$ describes being ignored by everyone around her when she was in obvious distress. On another occasion, she recalled being reprimanded for reaching out to a distressed colleague:

(Colleague) is under her desk in the fetal position sobbing and rocking. And so, I crawled under the desk with her and just held her. Well, people came up and said, 'It's none of your business.' In (country of assignment), you're supposed to let people be alone. And I thought, 'Fuck you. There's somebody obviously hurting.' And she was fine, she let me hold her. And I held her for about an hour. And I thought, 'What's wrong with this place?' And then she was out for six months, she was a six-month burnout leave. Yeah, but it's just horrible.

Ironically, these examples took place in a country with a generous staff wellness plan that included paid burnout leave. Significantly, it indicates that a wellness plan in and of itself is not 
sufficient but needs to be actively integrated into the organizational culture. After all, PH's account highlights how individual manager's actual disregard for staff well-being can trickle down, so that colleagues, under their own pressures, might also disregard each other's needs.

\section{Lack of Boundaries, Expectation of Working on Weekends and Holidays}

The many factors outlined above that contribute to the excessive workloads also contribute to a culture that ignores healthy boundaries. The commonplace expectation of working long hours necessarily leads to working during normally scheduled breaks. As SD described in one assignment, "I couldn't take a four-day weekend and not check email." My own experiences with one organization exemplify the failure to respect the boundaries between work and private that characterizes the aid industry. The same manager who rescinded my contract extension when I declined to give up home leave later hired me in another country. His management approach included calling me consistently during evening and weekend hours.

He further informed me that he expected me to be available " $24 / 7$ " despite my assignment being a non-emergency development program and despite my contract clearly stipulating office hours from 8:30am to 4:30pm. He and other managers would text me during vacation with non-urgent, negative news that I was unable to address at that moment. In a separate incident, an HQ-based program officer insisted I interrupt my home leave to conduct an evaluation of a project with which I was completely unfamiliar in a country to which I was not assigned. She called me on my first day home while I was playing with my young nephews whom I had not seen in a year to discuss the details of the evaluation. I took the call. 


\section{Management Insufficiently Aware of Signs of Burnout}

HQ staff and managers are insufficiently trained in recognizing the symptoms of burnout. That partially accounts for their lack of attention to aid workers well-being. Some organizations develop wellness plans, although, in such cases, as CN stated, these widely criticized plans are "window dressing" and that "staff care was a bit of a joke." In one of my posts, a colleague sought to use her extended PTO, which she had earned, to be with her family over the Christmas holiday. Our manager denied the request. She went over our manager's head to get HR involved. When he shared the story with me, he reflected, "I guess she was getting burned out, I didn't realize that." But no matter the reason, aid workers who do not believe that their managers care about their well-being will neither share their troubles nor request assistance, increasing the likelihood of burnout.

\section{Inadequate Human Resources Practices}

Poor human resources (HR) practices are endemic in the aid sector and lead to unqualified people being hired and promoted to higher level management positions. These poor HR practices include nepotism, a lack of 360-degree performance evaluations (where staff formally evaluate their supervisor) and failure to properly screen candidates. Aid organizations typically do not screen for mental health status, resiliency, and related issues upon hire or debriefing. The recruitment process can be long and laborious, often taking several months to identify a candidate, make an offer, and complete onboarding. Meanwhile, those on the ground are overworked while trying to fill in the staffing gaps. These gaps are further exacerbated when people burn out and quit or decide not to renew their contracts, perpetuating a vicious cycle. IN characterized HR as "not fulfilling its function." She explained how, during a large-scale disaster 
response, her organization "had millions of dollars" but "could not get the right people in place." IN attributed this to HR acting "more like procurement" rather than a proper human resources department, which meant that she could not turn to them for support or admit to being tired. When people ill-suited to the task are hired, however well-intentioned they may be, the result is inefficiency and duplication, which negatively impacts the entire team.

$\mathrm{CN}$ attributes the shortcomings of HR practice in aid to a failure to do "their due diligence in vetting people." One idiosyncrasy of HR policy in humanitarian aid is to deny present or former employees letters of recommendation and instead to only confirm the employee's title and dates of employment. This is done to protect the organization from lawsuits, but it also makes it difficult to identify problem employees who may otherwise be experienced and have good interviewing skills.

This same concern with liability and legal protection prevents organizations from firing employees who perform poorly or engage in inappropriate behavior. I once learned that a male employee berated our host-country partner so badly that he reduced a woman to tears. The manager at the host-country partner organization complained to our HQ staff and terminated their professional relationship, which meant that my co-worker was literally unable to do the very job he was hired to do. Not only was this individual not fired, but the matter was treated as a topic of amusement at the next staff meeting. In another instance, multiple aid workers accused a senior manager of sexual harassment and assault. Our organization allowed the man to resign rather than be fired, and, because of his years of experience and extensive professional network, he was quickly hired by another agency. This incident directly damaged the mental and physical well-being of the man's alleged victims and it also hurt the morale of the entire organization and rippled throughout the aid sector itself. Even today, many years after the fact, this case is widely 
remembered and discussed in the industry. In fact, two participants in this research brought up that incident during our conversations although neither of them had worked for the organization in question.

\section{Managers Untrained in People or Program Management Skills}

Poor HR practices can directly lead to hiring and promoting incompetent or untrained managers. This takes a toll on aid workers. DS burned out when he was in a heavy security situation without a lot of guidance or support from his HQ team. He described how when still relatively new to aid work he was "plopped into the middle of a conflict" by his organization-just given a car and some money and told to "go do good."

As PH mentioned and my own experience corroborates, many managers in international aid organizations "have never taken a management class in their life." It was certainly not part of the public health curriculum in the university I attended, and yet I was tasked with managing people from my very first assignment. Basic management techniques such as recognizing efforts and sacrifices made by staff were often lacking. OF describes how he burned out after spending two years in a large-scale disaster relief program making a "massive personal sacrifice for the company, [and] coming back there was virtually zero recognition of it." Some managers admit that, in hindsight, they would do things differently. RS shared that he got tired of the staff complaining about an tax issue that he did not consider a priority, so, although it was clearly very important to them, he just "blew it off"- an approach he now regrets. Like the rest of his staff, RS was under the immense pressure of project deadlines and donor requirements and sought efficiencies in putting off non-urgent staff complaints. 
CC shared his frustration with people at headquarters who had never worked in the field, yet "try to speak authoritatively about what they think is going on" in their desire to be perceived as experts. When they do visit the field, people from western developed countries often expected to be put in charge when they were "perhaps the least qualified individual[s] there." One exemplary anecdote $\mathrm{CC}$ shared involved their gender equity Program Manager insisting on sending single women, without escorts, to administer surveys house-to-house in a Muslim country. Such an approach was culturally unacceptable and dangerous, and his colleagues' insistence on this tone-deaf decision sparked a row between $\mathrm{CC}$ and management. The onset of the COVID-19 pandemic, according to CC, filtered out senior staff who, "should have retired a long time ago" but also led to the loss of the entire disaster unit which left the organization unable to manage the crisis. "To do this job effectively," CC commented, "when disaster hits, you run towards the disaster. You don't run away from it."

Humanitarian aid work, while moderately well remunerated, does not offer the financial possibilities of the private sector. People get into aid work, as elaborated above, because of a desire to do good, to travel, and for the spirit of adventure. Few managers enter the aid sector to put their management expertise to practice. This selection effect- of aid workers more motivated by endogenous affective goals than external financial rewards-also accounts for poor management practice endemic to the sector. IN recounted working for an NGO whose founding member excelled at raising funds and networking but was "ill-equipped" when it came to program management. This led to a very stressful situation for her and her colleagues.

Corruption is a problem in humanitarian aid, which further damages the quality of management practice. Working in weak institutional environments, with urgent pressure to distribute large amounts of aid quickly, facilitates corruption (Shipley 2019). During KE's first 
assignment as an aid worker, a prominent woman was caught stealing from a feeding program.

The other local staff were angry but felt too afraid and powerless to try to stop her. KE

subsequently learned that the Country Director failed to fire the woman because he was also

embezzling and did not want to draw too much attention to the books. She described both her

worry and anger at not being able to help resolve the issue:

Unfortunately, the Country Director was staggeringly corrupt. Staggeringly. The reason he was protecting her is because he was also siphoning off money. Yeah, it was just a catastrophe. But if I'd known more, I might have been able to protect the national staff better. I was really worried about the national staff. I mean, I was beyond furious. This woman was taking food from the nutritional feeding program.

This series of interconnected issues that lead to bad management in humanitarian aidhubris, corruption, lack of training, and lack of field experience-places a heavy burden on already overwhelmed workers. IN, for example, articulated that the stress of "old-fashioned, archaic decision-making" incompatible with the context of the field situation, was more physically and mentally draining than the stress of the work itself. Similarly, PH described feeling "trapped" when she was stationed at HQ for an assignment that required her frequent presence in the field. She was then forced to travel 287 days in one year, without her family, which left her exhausted and frustrated.

\section{Fear of Legal Liability}

The aid sector is characterized by a structural preoccupation with legal liability. Because workers are overseas in dangerous and unpredictable situations, the pursuit of legal protections is baked into the DNA of the aid industry. This further strips power and autonomy from workers, exacerbating burnout. In one case, this drive to "protect the organization," as PH put it, cost her multiple months'-worth of paid home leave. During the same assignment in which $\mathrm{PH}$ had to travel 287 days in one year, neither her supervisor nor HR took the time to go over her benefits 
with her, and, being so overwhelmed by the job, she failed to discover the benefit on her own.

She attributes this to the structural set up of HR in aid.

[It was] ridiculous, I was working 80 hours a week easily for three years. And I never took my home leave because I didn't realize we were entitled to it. I saw something in a handbook at one point, that I had missed my home leave. And I remember thinking, "Why couldn't somebody have alerted me?" So, their HR is not set up to protect people. It's more to protect the organization.

This drive to protect the organization at all costs can lead to insidious and bad faith

efforts to discredit workers. PH, for example, notes a pattern of organizations harassing workers when they file grievances against management. When someone formally complains, the organization "turns it around" and accuses the complainant of harassment as well. PH experienced this pattern first-hand when she filed a complaint. Moreover, the lawyer she found to defend her had defended more than 15 other women against this same organization.

Organizations use harassment and shame to shut down legal embroilments. PH, paraphrasing her lawyer's advice to her, described it as manipulation.

What he said to me was, the people on top are the ones who are expert in figuring out what motivated you to go into humanitarian work and turn it into shame by basically accusing you of something and you know, robbing the very work that it is that you're trying to contribute towards. He said they're such incredible manipulators to making you feel shame.

\section{Inadequate Housing or Non-Family Postings}

Aid organizations often organized shared housing for workers in the field. This can be stressful for workers for two reasons: 1) in new and stressful environments, privacy is paramount for mental health, and 2) the additional logistics of sharing quarters with strangers is

burdensome. KE describes the experience of shared housing in the field and highlights the lack of privacy. She further equates obligatory shared housing with a lack of organizational support for workers.

I have a bed with, you know, four other people in this room. And it's like immediate burnout almost, because you have no privacy. You're looking at, however many weeks or months of living like that. And your office is like, 'Yeah, yeah, just put up with it.' Why? This is the United States government, why do I have to put up with this ten months after a disaster? I mean, there were only four people sharing a tent in 
February. Why are there five people sharing a bedroom in September? Anyway... Yeah, so I've not worked with an organization that provided support for their people.

KE wanted to assure me that she is aware of her privilege just by having had a bed to sleep in but had shared the story to get across the aspects of mental health related to privacy.

Furthermore, family posts - mentioned by several of the interviewees as a good way to prevent burnout - are often limited due to security concerns. Aid workers with a spouse and children are then prohibited from bringing them along, which leads to missing and worrying about their family, and not having that support network on which to rely. RS explains how many positions in high-risk assignments only attract single applicants for this reason, as married aid workers understandably prefer to live with their families when possible. He also believes that many of those places could be family friendly but that the organizations do not want to take on the liability that would involve. This puts aid workers with families in a tough position, having to choose between putting them in a risky situation or living apart from them which comes with its own disadvantages.

\section{Why Aid Workers Accept Excessive Workloads and Poor Working Conditions}

Not all blame can be placed directly on the aid sector itself when it comes to accepting the unhealthy aid sector lifestyle, but aid organizations can certainly exploit workers' good will. Below I examine aid worker attributes that help explain why they tolerate such treatment.

\section{Aid Worker Work Ethic and Altruistic Nature}

Aid organization management understands that most aid workers come to the sector with a genuine, altruistic desire to help those in need. Aid workers, in general, have a strong work ethic and awareness of their own privilege. They are therefore predisposed to work long hours as 
a matter of both custom and pride. Aid workers' dedication to the beneficiaries of their work mean that they put great pressure on themselves to maintain a heavy workload. This is especially true in the immediate aftermath of a natural disaster but can last for the duration of the recovery phase. $\mathrm{CN}$ characterized this phenomenon as a mixture of passion and cleverness that leads to burnout. "The great thing about our business," he stated, "is there's a lot of passionate motivated people who actually are quite clever, and, in some cases run themselves right into the ground because they care so much.” PH offered a specific example of why she accepted the long hours while working in the horn of Africa:

I did a lot of work on FGM (female genital mutilation). And this woman told me, 'I just want to tell you there were 147 clitorises that were not cut because of you.' Yeah, so I hear that and I'm like, okay, so I can put up with 80-hour work weeks. That's worth it, right?

Additionally, traveling the world while helping people is an exhilarating - maybe even addictive - adventure (Lyng 2005, Roth 2015). SD described working 12 hours a day in a highrisk assignment in one breath and in another declared that she had been so excited to be there that she "literally would have done it for free as long as like housing and basic stuff was paid for." This exhilaration comes at least in part from realizing that she excelled at her job and felt a sense of belonging. She said, "It made me feel alive, it reminded me how that I belong in this place. And it reminded me that I'm really good at what I do when the shit hits the fan."

Altruistic dreams of helping others are frequently thwarted by the realities of the aid sector and the limitations of aid work that you would expect to see people who stay in the sector become increasingly cynical. When one interviewee reviewed the parts of his transcript that I selected as quotes, he wrote back that he thought he sounded like a curmudgeon and suggested that it may be time to retire. Perhaps the best advice to counter cynicism came from OF, who recommended dropping any "unrealistic expectations" of making a real, sustained improvement in the lives of others. 
Certain countries are subject to environmental conditions that are just going to keep happening, you know, droughts and floods and famines and all sorts of things. You might be able to put a few Band-Aids on to help people for the time being. As long as you realistically see that this is what you're doing, then you're going to probably suffer less burnout, you know, if you don't have unrealistic expectations of what you're doing.

\section{Reluctance to Seek Assistance}

The same work ethic, pride, and search for excitement that motivate workers' long, hard hours also discourage them for asking for breaks or assistance. When SD witnessed a poorly constructed improved explosive device (IED) set off on a bridge by a vehicle in front of hers and landing the vehicle in front of her in a ditch, she immediately joined others to help. What she did not do was seek medical or psychological treatment for it and went to her next assignment thinking, “Oh, I'm fine. Mind over matter, like, stop being negative.” Right after she developed an ear infection which had a domino effect and led to nerve damage. She recognized that there are humanitarian aid workers who "think they're Superman." CN admitted that he does not deal with burnout appropriately. He blames his Midwestern upbringing for giving him a "forge ahead, finish your contract sort of mentality." OF likened the excitement of his assignment to war:

It was just the most incredible, exhilarating and a great learning experience of my life, and also a humbling and most frustrating experience in my life. There was no time for burnout during it, you know, it was more like a war. And you're basically full-on adrenaline all the time.

Pride is also a major factor in workers' willingness to accept sub-optimal working conditions. Workers pride themselves on the number of countries they have worked in, working in hardship duty stations, getting tropical or lesser-known diseases, or being in conflict zones. OF described going to parties where "all these people were rattling off all the countries they had been in, as if there was some sort of notch in their belt. It was a sort of badge of honor." OF further shared that his own motivation to do humanitarian work was in part "egoic." I myself continue to be slightly disappointed that I never had malaria, and so I talk about the case of salmonella that landed me in the hospital. Aid workers are not without an ego. 


\section{Delayed Reaction to Burnout/Injury}

Many aid workers experience a delayed reaction to trauma or burnout, which further works against them in seeking better working conditions. Because there is no training or discussion around the signs and symptoms of burnout, one often fails to recognize the symptoms until well after the fact. SD described being held at gunpoint. Her reaction at the time was one of anger. She suppressed the trauma and fear until several days later when she broke down in tears. In another instance, SD was working six or seven days a week, 12 hours a day, and then was denied her R\&R for business purposes. Although she recognized that she was stressed, she failed to see it as burnout until after the fact. OF described a similar experience after working for two years:

I couldn't actually function. I mean, I was functioning at an extremely competent level when I was there, but when I got back here, I couldn't even bring myself to rent an apartment or anything. I just stayed with my brother and he and his wife looked after me for about three months. It was reverse culture shock, almost like a mini nervous breakdown.

That assignment, which he likened to a war zone, had kept him so busy and distracted from his own health that it was only when he returned to his home country that collapsed in exhaustion.

\section{Socializing with Others in the Aid Sector Is a Double-Edged Sword}

Aid workers often see their work as an opportunity to meet like-minded people, socialize, and in some cases, forge lifelong friendships. Nevertheless, socialization can increase the likelihood of burnout. DS' continued appetite for fieldwork stems from the camaraderie of working with a diverse team and creating something together. Yet, in the field, one's colleagues are also one's friend group, which means never being able to fully unplug from work. CN contrasts the experience of socializing in the field with working at an insurance company back home: 
I would say that the downside to that is, you're never able to detach from work, because everyone is sort of stressed about the same things and you talk about the same things and the same work. Whereas in a regular day to day life, you might leave your job at an insurance company, and you never talk about that again. You go out with your friends, and you don't have to worry about this. I would say that from a stress perspective, you never are able to disassociate yourself from the work because of where you're living and the social group that you've that you've made.

Cognizant of the mental health benefits of separating work and play, $\mathrm{CN}$ invited his staff to a Thanksgiving Day meal imposing one rule: no talking about work. Honoring the rule proved impossible as the guests began discussing work almost immediately. Not only is one never able to fully get away during a fieldwork situation, but additionally most of the people with whom one socializes are also in various stages of burnout, which intensifies the collective spirit of cynicism. In IN's experience in the field, when friends would gather for a drink, everyone would just complain and share their frustrations. Discovering that even the colleagues she most respected and admired were stressed out and cynical intensified her own exhaustion. Thus, socializing added to, rather than alleviated, her stress. 


\section{CHAPTER V: IMPLICATIONS AND CONCLUSIONS}

\section{Policy Implications}

This research describes how the aid sector, its individual organizations and management are structurally set up to facilitate burnout, thereby injuring their workers. Labor in aid is a seller's market. Workers are plentiful, and positions are scarce. This market is produced and maintained through the universal practice of short-term contracts. The sector's total dependence on limited soft money and the irregular and intense nature of disasters and conflicts produces an almost perfectly competitive market among aid organizations, which, in turn, strips worker power and facilitates exploitation. Further, the industry culture of machismo and stoicism means that wellness policies and programs are largely symbolic, and workers are discouraged from admitting to "weakness" and seeking assistance.

This exploitation creates what I describe as an "injury" and contributes to the emotional exhaustion and alienation that aid workers experience. The prevalence of this injury illuminates how individual efforts at coping are, alone, insufficient to prevent burnout. Aid workers seek the gratification of helping disadvantaged people and the thrill of working in foreign countries under rugged conditions. Instead, they are forced to work long hours with little support and end up emotionally exhausted and alienated from both their work and the people they are meant to be helping.

While the causal factors of endemic burnout in aid work are structural and sector-wide, the solutions lie with the organizations themselves. Donor agencies and aid organizations not only have a moral imperative to protect their workers from injury but doing so would also improve the efficacy of aid work and strengthen organizational fortitude over the long term. With this in mind, I address my second research question of what specific actions aid 
organizations can take to mitigate the widespread incidence of burnout in aid with a series of policy recommendations presented below.

\section{Policy Recommendations for the Aid Sector}

1. Create a staff-wellness resolution to be adopted sector-wide: Donor agencies and aid organizations large and small must collaborate in adopting a resolution that, well in line with their mission to ease suffering, staff-wellness be a priority. Such a resolution would ultimately benefit all key stakeholders as the flip side of burnout is efficacy: healthier staff provide better services to program recipients. Without this step, all other policy recommendations will be partially successful in reducing burnout at best.

2. De-stigmatize mental health care: Reduce the stigma by talking about mental health more frequently. Train people to recognize and counteract the signs of burnout in themselves and others. Send regular emails on wellness that includes both physical and mental health. Teach people that no one is immune from suffering from the symptoms of burnout. Remind workers what services are available and encourage their use.

3. Schedule periodic, mandatory mental health checks: Everyone has a story that they might be more willing to share if given a safe platform with a good listener. Quarterly check-ins by a trained specialist from a similar cultural background and language or even another colleague/mentor could be beneficial. This would help counteract the reluctance to "complain" outright about sensitive issues.

\section{Create and enforce a staff wellness policy with input from field-based staff: Take} the cultural needs of staff from the global south into account. Provide adequate time off, including separate time off for maternity/paternity leave, bereavement, and sick time. 
Reduce and monitor overtime hours and offer additional compensation for overtime. Establish a "no non-urgent emails/texts after hours" policy. Ensure that policies are universal and absolute and not subject to the whims of a manager. Include team building and social activities and, when possible, exercise equipment or gym memberships in the budget. Prioritize staff health over donor requirements and organizational reputation.

5. Conduct 360-degree performance reviews: Protocol dictates that staff should not "go above their bosses' head" with criticism, allowing poor management to thrive. Organizations must change these institutional values and provide opportunities for staff to review and evaluate their manager's performance. This will "air out" grievances rather than ignoring them and will thus reduce problematic management behavior.

6. Overhaul Human Resources: Hire an adequate number of staff to reduce excessive workloads and ensure coverage when someone is on leave. Ensure staff quality with full background checks and by asking for recommendations. Make private accommodations and family postings standard operating procedure. Allow friends and family to visit hardship duty stations.

7. Facilitate "personal" coping mechanisms: Finally, exercise, yoga/meditation, and social activities, while alone are insufficient to fend off burnout, do strengthen both physical and mental health. Organizations should facilitate such activities by offering group fitness classes, organizing social events in a variety of places, and ensuring access to exercise equipment. Ideally, such extracurricular activities would be based on worker input and thus vary with different cohorts of workers. 


\section{Strengths And Limitations}

This research pulls from the extensive cumulative professional experience of myself and the research participants and includes development assistance, emergency and disaster response, working in conflict zones, and more. One limitation of this study is that all the participants were in their 40s or older. The reluctance to seek help may be less pronounced in younger aid workers as they may be more likely to seek and openly discuss mental health issues, well-being, and treatment. If the stigma around mental health issues is in fact lessening, that is reason to celebrate. However, no amount of help-seeking behavior or self-care activities can eliminate the injury of burnout if field-based staff continue to work the long, grueling hours now common and people across the sector fail to acknowledge the systemic issues that are being faced by aid workers and organizations. Another limitation of the study was the lack of a representative sample and small number of aid workers who responded to the abridged poll although valuable descriptive information was collected.

\section{Suggestions for Further Research}

Space does not permit me to flesh out any difference in the prevalence and severity of burnout between aid workers responding to a natural disaster or systemic poverty and those working in a conflict zone, but more attention could be given to those differences in future research. Further research would also benefit by including younger, less experienced participants to determine if younger aid workers experience their work differently than older aid workers. This would help aid organizations take better care of their field-based employees of all ages and years of experience. Another interesting focus would be to compare those aid workers who 
report never having ever experienced burnout with those that have. What are they or their organizations doing differently that others can learn from and emulate?

Other relevant foci for further research are the burnout experiences of aid workers based in their organizations' headquarters and how one employee - especially a supervising manager or close colleague - experiencing burnout can directly or indirectly affect the mental well-being of the rest of the team. Finally, the stresses and frustrations experienced by local aid worker staff, who earn less, have fewer privileges than international staff and are forced to deal with wellintentioned foreigners who often do not speak their language nor understand their culture, are not to be minimized. Further research to reduce those frustrations would benefit the entire team.

\section{Conclusion}

In Western society, we tend to view one's health as the outcome of personal decisions. This research points a systemic problem: the structural conditions in the "DNA" of the humanitarian aid sector lead to the injury of burnout regardless of one's individual choices and coping mechanisms. Therefore, it is incumbent upon the aid sector itself - both the donor agencies and aid organizations - to resolve to address the issue of aid worker burnout as injury.

The effects burnout are truly traumatic for some aid workers. Aid workers practice a wide range of health-seeking and social activities such as dancing, meditation, yoga, outdoor recreation, and playing music, yet burnout/injury remains pervasive in the sector. While they should continue to engage in healthy activities, aid workers must recognize that their individual burnout experience is part of a structural and systemic issue and that any individual practices must be accompanied by sector-wide organizational changes. No amount of yoga can stave off the injury that the excessive workloads and burdensome demands inflict on aid workers. This 
recognition is important to exonerate workers themselves of the feelings of guilt, self-blame, and weakness that often accompany burnout and to motivate workers to hold their employers accountable.

As inequality, poverty, vulnerability, and conflict persist around the world - intensified and rendered less predictable by the vagaries of climate change - the work of humanitarian aid is becoming ever more important. Furthermore, the demand for relief assistance will continue to grow in both wealthy and poorer countries. Worryingly, as wealthy donor countries continue to experience or prepare for more frequent natural disasters, they may allocate fewer funds to assist poorer, more vulnerable countries. This diversion of funding would lead to ever more cashstrapped international aid projects with too few staff hired to implement them.

The prevalence and intensity of burnout/injury among aid workers represents an existential threat to the sector. The short-term contract model serves organizational interests by being cost-effective, allowing for workforce flexibility in an unpredictable field, and concentrating decision-making power in the hands of senior management. However, this model has deleterious effects on worker productivity and organizational efficiency, essentially guaranteeing that these organizations will have ever less impact while consuming ever more resources. It is, therefore, crucial that organizations and managers take the necessary steps to ensure the health and vitality of their staff so that they may continue to perform their necessary functions in providing aid wherever it is needed.

The irony that the aid sector is set up in such a way that it causes harm and injury to the very people who are called to help others is particularly regrettable. The fact that aid workers accept such injurious conditions to continue to help is even more so. Ultimately, the onus on prioritizing staff wellness is on the management of donor agencies and aid organizations who 
must come together to reflect more deeply on their actual mission. Meanwhile, my hope is that aid workers themselves lead the charge to reduce the stigma around burnout in the aid sector and demand healthier working conditions. 


\section{REFERENCES}

Ager, A., E. Pasha, G. Yu, T. Duke, C. Eriksson, and B. Lopes Cardozo. 2012. "Stress, Mental Health, and Burnout in National Humanitarian Aid Workers in Gulu, Northern Uganda.” Journal of Traumatic Stress (25):713-720.

Albuquerque, Sara, Anneli Eriksson, and Helle M. Alvesson. 2018. "The Rite of Passage of Becoming a Humanitarian Health Worker: Experiences of Retention in Sweden.” Global Health Action 11(1):1417552.

Asgary Ramin and Katharine Lawrence. 2014. "Characteristics, Determinants and Perspectives of Experienced Medical Humanitarians: A Qualitative Approach.” British Medical Journal 4:e006460.

Blanchetière, Pascale. 2006. "Resilience of Humanitarian Aid Workers.” Master's dissertation at the Institute for Development Policy and Management, University of Manchester, UK.

Brown, William A. and Carlton F. Yoshioka. 2003. "Mission Attachment and Satisfaction as Factors in Employee Retention." Nonprofit Management \& Leadership 14(1):5-15.

Casey, John. 2016. What is the Role of For-Profit Companies in International Aid and Development. Conference Paper for Arnova Annual Conference. ResearchGate Retrieved from (https://www.researchgate.net/publication/310766680_What_is_the_Role_of_ForProfit_Companies_in_International_Aid_and_Development)

CauseIQ. 2021. "International Relief Organizations.” Retrieved from (https://www.causeiq.com/directory/international-relief-organizations-list/)

Collins, Randall. 1990. "Stratification, Emotional Energy, and the Transient Emotions." in T. Kemper (ed.) Research Agendas in the Sociology of Emotions, Albany, NY: State University of New York Press. 
Curling, Penelope \& Kathleen B. Simmons. 2010. "Stress and Staff Support Strategies for International Aid Work.” Intervention 8(2):93 - 105.

Dahlgren, Atti-La, Lisa DeRoo, Jacqueline Avril, Gerard Bise, Louis Loutan. 2009. "Health Risks and Risk-Taking Behaviors Among International Committee of the Red Cross (ICRC) Expatriates Returning from Humanitarian Missions." Journal of Travel Medicine, 16(6): 382-390.

Damania, Zubin. 2019. “It's Not Burnout, It's Moral Injury.” Turntable Health, Retrieved from (https://zdoggmd.com/moral-injury/).

Doidge, Mark and Elisa Sandri. 2019. "Friends That Last a Lifetime: The Importance of Emotions Amongst Volunteers Working with Refugees in Calais." The British Journal of Sociology 70(2):463-480.

Durkheim, Émile. 1915. The Elementary Forms of the Religious Life, a Study in Religious Sociology. London: G. Allen \& Unwin; New York: Macmillan.

Edwards, Sebastian. 2014. "Economic Development and the Effectiveness of Foreign Aid: A Historical Perspective." Vox EU/Center for Economic and Policy Research (CEPR). Retrieved from (https://voxeu.org/article/development-and-foreign-aid-historicalperspective).

Ellis, Carolyn, Tony E. Adams \& Arthur P. Bochner. 2011. "Autoethnography: An Overview” Historical Social Research 36(4): 273-290.

Foster, William and Gail Fine. 2007. "How Nonprofits Get Really Big.” Stanford Social Innovation Review, 5(2): 46-55.

Fukami, Cynthia V. and Erik W. Larson. 1984. "Commitment to Company and Union: Parallel Models.” Journal of Applied Psychology 69(3):367-371. 
Heuser, Eric Anton. 2012. "Befriending the Field: Culture and Friendships in Development Worlds." Third World Quarterly 33(8): 1423-1437.

Hochschild, Arlie R. 1983. The Managed Heart: Commercialization of Human Feeling.

Berkeley, CA: University of California Press.

Humanitarian Coalition. 2021. Retrieved from: https://www.humanitariancoalition.ca/fromhumanitarian-to-development-aid.

Humanitarian Outcomes. 2020. "The Aid Worker Security Database” London, UK:

Humanitarian Outcomes. Retrieved from

(https://aidworkersecurity.org/incidents/reports/victims).

Jachens, Liza, Jonathan Houdmont, and Roslyn Thomas. 2019 "Effort-Reward Imbalance and Burnout Among Humanitarian Aid Workers.” Disasters 43: 67-87.

Jinkerson, Jeremy. 2016. "Defining and assessing moral injury: A syndrome perspective." Traumatology, 22(2): 122-130.

Kallman, Meghan E. 2015. "Material, Emotional and Professional Dynamics: Idealism, Commitment and Self-Regulation in the Peace Corps" Pp. 73-99 in Materiality, Rules and Regulations: New Trends in Management and Organization Studies edited by de Vaujany, F-X., Mitev, N., Mukherjee, A., and Lanzara, GF. London, UK: Palgrave Macmillan.

Lewandowski, Cathleen A. 2003. "Organizational Factors Contributing to Worker Frustration: The Precursor to Burnout." Journal of Sociology and Social Welfare. XXX(4):175-185. Lois, Jen. 2001. "Peaks and Valleys: The Gendered Emotional Culture of Edgework." Gender \& Society 15(3):381-406.

Lyng, Stephen. 1990. "Edgework: A Social Psychological Analysis of Voluntary Risk Taking.” American Journal of Sociology 95:851-886. 
Lyng, Stephen. 2005. "Sociology at the Edge: Social Theory and Voluntary Risk Taking.” In Edgework. The Sociology of Risk-Taking, edited by S. Lyng, 17-49. New York: Routledge.

MacPherson, Robert I. S. and Frederick M. Burkle, Jr. 2020. "Humanitarian Aid Workers: The Forgotten First Responders” Prehospital and Disaster Medicine 36(1): 111-114.

Marx, K. (1964). Economic and philosophic manuscripts of 1844. New York: International Publishers.

Maslach, Christina. 1993. "Burnout: A Multidimensional Perspective.” In Journal of Organizational Behavior 2(2):99-113. Series in applied psychology: Social issues and questions. Professional burnout: Recent developments in theory and research edited by Schaufeli, W.B, C. Maslach, and T. Marek. Taylor \& Francis Pp. 19-32.

Maslach Christina, Wilmar B. Schaufeli, Michael P. Leiter. 2001. "Job Burnout.” Annual Review of Psychology 52:397-422.

McCormack, Lynne and Samantha Bamforth. 2019. "Finding Authenticity in Altruistic Identity: The "Lived" Experience of Health Care Humanitarians Deployed to the 2014 Ebola Crisis.” Traumatology 25(4):289-296.

Michie, Susan and Anne Cockcroft. 1996. “Overwork can kill.” British Medical Journal 312:921 doi:10.1136/bmj.312.7036.921.

Mottaz, Clifford J. 1988. "Determinants of Organizational Commitment.” Human Relations 41(6):467-482.

Oberholster, Abraham J., Ruth Clarke, Mike Bendixen, and Barbara Dastoor. 2013. "Expatriate Motivation in Religious and Humanitarian Non-Profit-Organizations.” Journal of Global Mobility 1(1):7-27. 
O’Hare, James. 2017. "The History of US Foreign Aid and Why It's as Important as Ever."

Global Citizen. Retrieved from (https://www.globalcitizen.org/en/content/united-statesforeign-aid-history-trump/?template=next).

Phillips, Keri. 2013. “The History of Foreign Aid.” The Australian Broadcasting Company. Retrieved from (https://www.abc.net.au/radionational/programs/rearvision/the-history-offoreign-aid/5162100).

Porter, Benjamin and Ben Emmens. 2009. "Approaches to Staff Care in International NGOs." For People in Aid/InterHealth. Pp 1-62.

Porter, L. W., R.M. Steers, R.T. Mowday, and P.V. Boulian. 1974. “Organizational Commitment, Job Satisfaction, and Turnover Among Psychiatric Technicians." Journal of Applied Psychology 59:603-609.

Roth, Silke. 2012. "Professionalization Trends and Inequality: Experiences and Practices in Aid Relationships." Third World Quarterly 33:1459-1474.

Roth, Silke. 2015. “Aid Work as Edgework - Voluntary Risk-taking and Security in Humanitarian Assistance, Development and Human Rights Work.” Journal of Risk Research 18(2):139-155.

Roth, Silke. 2015. The Paradoxes of Aid Work: Passionate Professionals. New York, NY: Routledge.

Salamon, Lester M. 1994. "The Rise of the Nonprofit Sector" Foreign Affairs 73(4):109-122.

Schnell, Tatjana, Thomas Höge, and Wolfgang G. Weber. 2019. “'Belonging’ and its Relationship to the Experience of Meaningful Work.” Pp. 165-185. The Oxford Handbook of Meaningful Work edited by R. Yeoman, C. Bailey, A. Madden, and M. Thompson. Oxford, UK: Oxford University Press. 
Sheik, Mani, Maria Isabel Gutierrez, Paul Bolton, Paul Spiegel, Michel Thieren, and Gilbert Burnham. 2000. “Deaths Among Humanitarian Workers.” British Medical Journal 321(7254: 166-168).

Shipley, T., 2019. Managing corruption challenges in humanitarian settings. Transparency International.

Strohmeier, Hannah and Willem Scholte. 2015. "Trauma-Related Mental Health Problems Among National Humanitarian Staff: A Systematic Review of the Literature.” European Journal of Psychotraumatology 6: article 28541. Retrieved from (https://www.ncbi.nlm.nih.gov/pubmed/26589256).

Threlkeld, Kristy. 2021. “Employee Burnout Report: COVID-19’s Impact and 3 Strategies to Curb It" Retrieved from (https://www.indeed.com/lead/preventing-employee-burnoutreport).

Bureau of Labor Statistics, U.S. Department of Labor, Occupational Outlook Handbook, Social and Human Service Assistants. Retrieved from (https://www.bls.gov/ooh/communityand-social-service/social-and-human-service-assistants.htm).

Van Brabent, Koenraad. 2000. “Operational Security Management in Violent Environments: A Field Manual for Aid Agencies." Good Practice Review. London: Humanitarian Policy Group, Overseas Development Institute.

Wall, Sarah. 2006. “An Autoethnography on Learning About Autoethnography” International Journal of Qualitative Methods 5(2): 146-160.

Wall, Sarah. 2016. "Toward a Moderate Autoethnography." International Journal of Qualitative Methods 15(1): 1-9. 
Young, Tarli K.H., Kenneth I. Pakenham, and Michael F. Norwood. 2018 “Thematic Analysis of Aid Workers' Stressors and Coping Strategies: Work, Psychological, Lifestyle and Social Dimensions." Journal of International Humanitarian Action 3(19). 


\section{APPENDIX A: PARTICIPANT DEMOGRAPHICS AND EXPERIENCE}

\begin{tabular}{|c|c|c|c|c|c|c|c|c|}
\hline $\begin{array}{l}\text { Parti- } \\
\text { cipant }\end{array}$ & Age & $\begin{array}{l}\text { Race/ } \\
\text { Ethni- } \\
\text { city }\end{array}$ & Sex & $\begin{array}{l}\text { Country } \\
\text { of origin }\end{array}$ & $\begin{array}{c}\text { Regions/countries of } \\
\text { service }\end{array}$ & $\begin{array}{l}\text { Years } \\
\text { in the } \\
\text { aid } \\
\text { sector }\end{array}$ & Types of aid work & Role \\
\hline $\mathrm{CC}$ & $60 \mathrm{~s}$ & White & Male & USA & $\begin{array}{l}\text { Puerto Rico, Australia, } \\
\text { Indonesia, Timor } \\
\text { Leste, India, } \\
\text { Cambodia, and } \\
\text { Vanuatu plus } 54 \\
\text { countries while in HQ }\end{array}$ & 29 & $\begin{array}{l}\text { Species conservation, } \\
\text { protected area } \\
\text { management, } \\
\text { sustainable } \\
\text { agriculture, fisheries }\end{array}$ & $\begin{array}{l}\text { Implementing staff, } \\
\text { manager, and consultant/ } \\
\text { technical advisor }\end{array}$ \\
\hline $\mathrm{CN}$ & $40 \mathrm{~s}$ & White & Male & USA & $\begin{array}{l}\text { Guyana, El Salvador, } \\
\text { Sri Lanka, Indonesia, } \\
\text { Lao PDR, } \\
\text { Jordan/Syria, Lebanon }\end{array}$ & 21 & $\begin{array}{l}\text { Development, } \\
\text { disaster and } \\
\text { emergency response, } \\
\text { and conflict }\end{array}$ & $\begin{array}{l}\text { Implementing staff, } \\
\text { manager, and consultant/ } \\
\text { technical advisor }\end{array}$ \\
\hline DS & $50 \mathrm{~s}$ & White & Male & USA & $\begin{array}{l}\text { Bosnia Hercegovina, } \\
\text { Croatia, Serbia, } \\
\text { Paraguay, Guatemala, } \\
\text { Ecuador, Colombia, } \\
\text { Chile, Caribbean, } \\
\text { Thailand, Myanmar- } \\
\text { Burma, Bangladesh, } \\
\text { Nepal, Pakistan, } \\
\text { Malaysia, Philippines, } \\
\text { Fiji }\end{array}$ & 24 & $\begin{array}{l}\text { Development, } \\
\text { disaster and } \\
\text { emergency response, } \\
\text { and conflict }\end{array}$ & $\begin{array}{l}\text { Implementing staff, } \\
\text { manager, and consultant/ } \\
\text { technical advisor }\end{array}$ \\
\hline IN & $50 \mathrm{~s}$ & Asian & Female & $\begin{array}{l}\text { Kenya/ } \\
\text { UK }\end{array}$ & $\begin{array}{l}\text { Afghanistan, Albania, } \\
\text { Bangladesh, Bhutan, } \\
\text { Brazil, Brussels, } \\
\text { Bulgaria, Cambodia, } \\
\text { China, Czech } \\
\text { Republic, Estonia, The } \\
\text { Gambia, Guyana, } \\
\text { India, Indonesia, } \\
\text { Jordan, Lebanon, } \\
\text { Latvia, Lao PDR, } \\
\text { Lebanon, Lesotho, } \\
\text { Lithuania, Macedonia, } \\
\text { Malawi, Maldives, } \\
\text { Myanmar, Nepal, } \\
\text { Nicaragua, Romania, } \\
\text { Pakistan, Peru, The } \\
\text { Philippines, Poland, } \\
\text { Solomon Islands, Sri } \\
\text { Lanka, Slovakia, } \\
\text { Syria, Thailand, } \\
\text { Turkey, UK, USA, } \\
\text { Vietnam, Zimbabwe }\end{array}$ & 23 & $\begin{array}{l}\text { Disaster, conflict, } \\
\text { transitional and } \\
\text { international } \\
\text { development }\end{array}$ & $\begin{array}{l}\text { Implementing staff, } \\
\text { manager, and consultant/ } \\
\text { technical advisor }\end{array}$ \\
\hline $\mathrm{KE}$ & $50 \mathrm{~s}$ & White & Female & USA & $\begin{array}{l}\text { South Sudan, Kenya, } \\
\text { Central African } \\
\text { Republic, Burundi, } \\
\text { Chad, Thailand, } \\
\text { Myanmar, Iraq, } \\
\text { Pakistan, Syria, Latin } \\
\text { America, the } \\
\text { Caribbean }\end{array}$ & 16 & $\begin{array}{l}\text { Development and } \\
\text { conflict }\end{array}$ & $\begin{array}{l}\text { Consultant/ technical } \\
\text { advisor }\end{array}$ \\
\hline $\begin{array}{l}\text { MQ - } \\
\text { author }\end{array}$ & $50 \mathrm{~s}$ & White & Female & USA & $\begin{array}{l}\text { Bolivia, Peru, } \\
\text { Ecuador, Dominican } \\
\text { Republic, Haiti, } \\
\text { Kenya, Eritrea, } \\
\text { Uganda, Nigeria, } \\
\text { Ghana, Malawi, } \\
\text { Vietnam, Indonesia }\end{array}$ & 13 & $\begin{array}{l}\text { Development, } \\
\text { disaster and } \\
\text { emergency response }\end{array}$ & $\begin{array}{l}\text { Implementing staff, } \\
\text { manager, and consultant/ } \\
\text { technical advisor }\end{array}$ \\
\hline
\end{tabular}

\section{(Appendix continues)}




\section{APPENDIX A: PARTICIPANT DEMOGRAPHICS AND EXPERIENCE, continued}

\begin{tabular}{|c|c|c|c|c|c|c|c|c|}
\hline $\begin{array}{l}\text { Parti- } \\
\text { cipant }\end{array}$ & Age & $\begin{array}{l}\text { Race/ } \\
\text { Ethni- } \\
\text { city }\end{array}$ & Sex & $\begin{array}{l}\text { Country } \\
\text { of origin }\end{array}$ & $\begin{array}{l}\text { Regions/countries of } \\
\text { service }\end{array}$ & $\begin{array}{l}\text { Years } \\
\text { in the } \\
\text { aid } \\
\text { sector }\end{array}$ & Types of aid work & Role \\
\hline $\mathrm{OF}$ & $70 \mathrm{~s}$ & White & Male & Australia & $\begin{array}{l}\text { Papua New Guinea, } \\
\text { Indonesia, Malaysia, } \\
\text { Bangladesh, China, } \\
\text { Russia, Philippines, } \\
\text { Congo (DRC), } \\
\text { Canada, US, Brazil, } \\
\text { Mauritania, Cook } \\
\text { Islands, Kazakhstan, } \\
\text { Mexico, New Zealand, } \\
\text { Solomon Islands, } \\
\text { Bangladesh, Qatar }\end{array}$ & 8 & $\begin{array}{l}\text { Post disaster } \\
\text { reconstruction and } \\
\text { geotechnical } \\
\text { development }\end{array}$ & $\begin{array}{l}\text { Implementing staff, } \\
\text { manager, and consultant/ } \\
\text { technical advisor }\end{array}$ \\
\hline $\mathrm{PH}$ & $50 \mathrm{~s}$ & White & Female & USA & 98 countries & 17 & $\begin{array}{l}\text { Development, } \\
\text { disaster and } \\
\text { emergency response, } \\
\text { and conflict }\end{array}$ & $\begin{array}{l}\text { Implementing staff, } \\
\text { manager, and consultant/ } \\
\text { technical advisor }\end{array}$ \\
\hline $\mathrm{RS}$ & $60 \mathrm{~s}$ & $\begin{array}{l}\text { White/ } \\
\text { Latin }\end{array}$ & Male & Argentina & $\begin{array}{l}\text { Central America, } \\
\text { Caribbean, Indonesia, } \\
\text { Sri Lanka, Maldives }\end{array}$ & $20+$ & $\begin{array}{l}\text { Development, } \\
\text { disaster response and } \\
\text { reconstruction, and } \\
\text { conflict }\end{array}$ & $\begin{array}{l}\text { Implementing staff and } \\
\text { manager }\end{array}$ \\
\hline SD & $50 \mathrm{~s}$ & White & Female & USA & $\begin{array}{l}\text { Congo (DRC), South } \\
\text { Sudan, Nigeria, } \\
\text { Uganda, Myanmar }\end{array}$ & 7 & Conflict & $\begin{array}{l}\text { Implementing staff and } \\
\text { manager }\end{array}$ \\
\hline $\mathrm{VH}$ & $40 \mathrm{~s}$ & White & Female & USA & $\begin{array}{l}\text { Vietnam, Haiti, Sub- } \\
\text { Saharan Africa, } \\
\text { Cambodia, Indonesia, } \\
\text { Jordan, Thailand }\end{array}$ & 22 & $\begin{array}{l}\text { Development, } \\
\text { disaster and } \\
\text { emergency response }\end{array}$ & $\begin{array}{l}\text { Manager and consultant/ } \\
\text { technical advisor }\end{array}$ \\
\hline
\end{tabular}




\section{APPENDIX B: AID WORKER INTERVIEW GUIDE}

Intro: A bit about me, my research topic, you signed the consent form, it's being recorded, let's begin:

\section{Motivations}

1. Tell me how and why you got into the humanitarian aid sector - what motivated you to join, what did you like about it? Have your motivations changed over time?

\section{Aid work experience}

2. How long and in what roles have you worked in the humanitarian aid field altogether? Where have you worked and lived?

3. How would you describe your working environment and living conditions? Is the workload manageable? Do you feel safe? Do you feel like you are making a difference or a real contribution?

\section{Relationships}

4. Tell me about your personal interactions with people in your office. How would you describe your relationship with your colleagues? Your supervisor? How is your relationship with the staff at your headquarters?

\section{Personal coping mechanisms}

5. What are some things you've done to reduce stress when working in the field? Was that effective? What do you wish you had done differently?

\section{Organizational stress reduction}

6. What are some of the things that your organization does to help you reduce stress? How effective would you say they are in general? 
7. As mentioned in my invitation letter, burnout is often described as some combination of the inability to concentrate, listlessness, feeling cynical, and decreased productivity. You reported that you have personally experienced at least one of the symptoms of "burnout" while working as a humanitarian aid worker. What was happening in your life that you believe led to burnout?

8. Did you raise the issue of burnout or your mental health to anyone in your organization? (If yes), who did you talk to and how did they react? Were you satisfied with their reaction? What do you wish they had done differently? (If no), why not? Is there anyone else that you can talk to if you feel isolated, frustrated, angry, or depressed?

\section{For managers}

9. Were you ever a manager in the field/HQ? (If yes), did you ever see your staff experiencing the symptoms of burnout? (If yes), what did you do? Was it effective? What do you wish you had done differently?

10. Imagine that you are put in charge of writing your organization's staff wellness policy. What are the top changes that you would make to reduce the likelihood of field staff experiencing burnout?

11. Is there anything else you'd like to share with me before we finish up the interview? 


\section{APPENDIX C: AID WORKER POLL}

Q1 This survey is for people who have worked as an international humanitarian aid worker, whether in development, disaster response, and/or conflict resolution. Thank you for your input!

How many years in total have you worked in the humanitarian aid field, including as a volunteer?

Less than 1 year

1-4 years

5-9 years

10-14 years

15 or more years

Q2 Were you stationed internationally, in headquarters, or both?

Internationally

Headquarters

Both 
Q3 Burnout is often described as feeling emotionally exhausted, cynical, or incompetent in the face of acute or chronic stressors.

Have you ever experienced the symptoms of burnout while working as a humanitarian aid worker?

Never

Occasionally

Often

All the time

Q3.1 On a scale from $1-10$, with $1=$ mild and $10=$ severe, how severe would you say your worst experience with burnout was?

$$
\begin{array}{llllllllll}
1 & 2 & 3 & 4 & 5 & 6 & 7 & 8 & 9 & 10
\end{array}
$$

Q4 Overall, how seriously would you say your organization takes staff wellness, particularly around mental health issues and the prevention of burnout?

Extremely seriously - top priority

Moderately seriously

Slightly seriously

Not seriously at all 
Q5 Does your organization presently offer free employee counseling?

Yes

No

Q5.1 Overall, how effective would you say free employee counseling is in reducing your stress?

Extremely effective

Very effective

Moderately effective

Slightly effective

Not effective at all

I never had the counseling

Q6 If you were put in charge of writing your organization's staff wellness policy, what would you include to prevent or alleviate international staff burnout? List as many items as you like. 